\title{
Regenerative cooling using elastocaloric rubber: analytical model and experiments
}

\author{
Gael Sebald ${ }^{1}$, Atsuki Komiya ${ }^{1,2}$, Jacques Jay ${ }^{3}$, Gildas Coativy ${ }^{4}$, Laurent \\ Lebrun $^{4}$
}

${ }^{1}$ ELyTMaX UMI 3757, CNRS - Université de Lyon - Tohoku University, International Joint Unit, Tohoku University, 980-8577, Sendai, Japan

${ }^{2}$ Institute of Fluid Science, Tohoku University, 980-8577, Sendai, Japan.

${ }^{3}$ Univ. Lyon, CNRS, INSA-Lyon, CETHIL, UMR5008, F-69621, Villeurbanne, France

${ }^{4}$ Univ. Lyon, INSA-Lyon, LGEF, EA682, F-69621, Villeurbanne, France

Corresponding author: gael.sebald@insa-lyon.fr

Caloric materials exhibit significant entropy variations when applying appropriate excitation, pushing forward the development of solid-state cooling systems. Their development includes materials' properties optimization, with a focus on their adiabatic temperature change when driven at their limit. In order to sustain the device development, an analytical model for regenerative cooling systems is presented in this work. It consists of a caloric material driven cyclically so that it exhibits harmonic temperature variations, whereas an oscillating fluid layer is exchanging heat with the caloric material, leading to a net heat flux along one given direction. The heat transfer equation was solved analytically for harmonic excitation along the direction perpendicular to caloric materials layers separated by fluid layers. In a second step, the problem was solved along an axis parallel to the layers. In order to validate the model, an experimental proof of concept was developed based on a natural rubber tube inside which water flows harmonically. The comparison between model and experiment is given, while the model highlights the importance of the thermal boundary layer, and how the geometry of the device compensates easily the low thermal conductivity of natural rubber.

Keywords: solid-state cooling, regenerative cooling, natural rubber, caloric materials, elastocaloric

\section{Introduction}

From the last two centuries, four generations of refrigerant gases were successively used in refrigeration systems, each new generation solving a previous performance / 
environmental issue. Continuous effort was being put in order to further improve this trade-off [1]. Alternatively, efforts were deployed on the development of solid state refrigeration systems $[2,3]$ which might lead to high performance systems (coefficient of performance : $\mathrm{COP}>5$ ), while allowing high miniaturization as well as suppressing high speed moving parts and vibrations from the cooling devices. Three types of materials have been more or less deeply investigated: magnetocaloric materials, electrocaloric materials and elastocaloric/barocaloric materials. Currently, a lot of works have been devoted to the magnetocaloric effect [4-6] and to the electrocaloric effect [79]. They generally focused on the characterization techniques (indirect methods versus direct methods of measurement), and the enhancement of the effect by developing new materials or new strategies to drive them (i.e. their use near a phase transition).

Fewer studies addressed the design of thermal machines based on the magnetocaloric effect, the electrocaloric effect, or elastocaloric effect. Caloric materials exhibit time variations of temperature, generated by the caloric effect. A cooling device therefore requires a system for converting time variations into spatial gradients. One straightforward solution is to put the caloric material in contact with the hot reservoir when the temperature is high, and then to move it in contact with the cold reservoir when its temperature is low. This constitutes the class of "single stage devices". Several examples are available in the literature for electrocaloric [10-14] and elastocaloric effects $[15,16]$.

Alternatively, one of the most promising consists of active caloric regeneration, where a fluid is moving synchronously between or around caloric material generating cyclic temperature variations $[3,17,18]$. Several experimental prototypes were investigated, with for example the pioneering work by Brown [19] for magnetocalorics and Sinyavky [20-23] for electrocalorics, followed by numerous developments in recent years [24- 
30]. The design is not straightforward - especially the geometrical considerations since the complex heat and mass transfer do not have simple solutions.

In the elastocaloric materials family, some soft polymers exhibit rather large elastocaloric activity $[31,32]$ due to the close link between entropy and elasticity. Natural rubber exhibits a very large effect, thanks to the strain induced crystallization [33]. In addition, the application of a pre-elongation allows a smaller relative strain, while keeping significant elastocaloric activity (adiabatic temperature change $>2{ }^{\circ} \mathrm{C}$ ) [34]. Elastocaloric materials should be optimized not only in terms of the largest adiabatic temperature change, it should include also the thermal properties, such as specific heat and thermal conduction. As experimental testing of all possible solutions is not accessible in a comprehensive manner, modeling may bring a relevant tool for screening different design solutions. Finite Element Method [35,36] appears as a straightforward solution, as well as other 2D numerical solving schemes [37-40] or even 1D approximation [41,42], but allows hardly the definition of figures of merit.

The key questions are therefore: How far the thermal properties of caloric materials affect the performances of a cooling device? To what extent geometrical optimization may counterbalance inadequate thermal properties? How to design a performant cooling device?

In this framework, this article presents an analytical model for simulating an active regenerative caloric cooling using any caloric material. The objective is to determine figure of merit of the cooling device, from the properties of the active material and of the fluid, as well as the geometry of the system. It is based on a two-step solving of coupled thermomechanical diffusion equations in harmonic regime. In section 2 is presented the model with its assumptions and solving, keeping fully analytical solutions. 
Key figures of elastocaloric cooling in a regenerative system are discussed. For model validation through comparison with experiments, several assumptions are waived, leading to a numerical solving and is detailed in section 3 of the article. The section 4 then presents an experimental setup of a regenerative cooling proof of concept using natural rubber as elastocaloric materials. Some results are given along with their comparison with modelling results, and showing the validity of the model.

\section{Model definition}

\subsection{Definition of the system to be modelled}

Let consider an active material exhibiting a caloric coupling, which could be electrocaloric, elastocaloric or magnetocaloric. It was assumed that it is driven with a harmonic solicitation of angular frequency $\omega$ leading to a body heat source $Q_{\text {vol }} i(t)$ inside the material writing

$Q_{v o l_{-} i}(t)=q_{i} e^{j \omega t}$

As a result, in adiabatic mode, the temperature signal writes $T_{i}(t)=\frac{q_{i}}{c_{i}} e^{j \omega t}$, where $c_{i}$ is the volumetric heat capacity. The difference between maximum and minimum temperature defined as $\Delta T_{a d}=\frac{2 q_{i}}{c_{i}}$ and corresponds to the peak-to-peak amplitude of temperature signal.

The model did not consider the details of the excitation nor the losses of the solicitation (such as dielectric losses or mechanical losses in the case of electrocaloric or elastocaloric couplings). The active material was considered as a layer of infinite lateral dimensions (along axis $\mathrm{x}$ and $\mathrm{y}$ ). It is surrounded by fluid layers, which constitute infinite layers subjected to a motion $v_{i}(x, t)$ along $\mathrm{x}$ axis 
$v_{i}(t)=v_{i} e^{j \omega t}$

The problem formulation and solving was adapted from a model proposed for thermoacoustic refrigeration device, as described in [43-45] where the complex heat and mass transfer of resonant acoustic waves in a parallel layers system is solved in a two-step 1D solving scheme for simplifications in harmonic regime.

The system to be modeled in displayed in Figure 1.

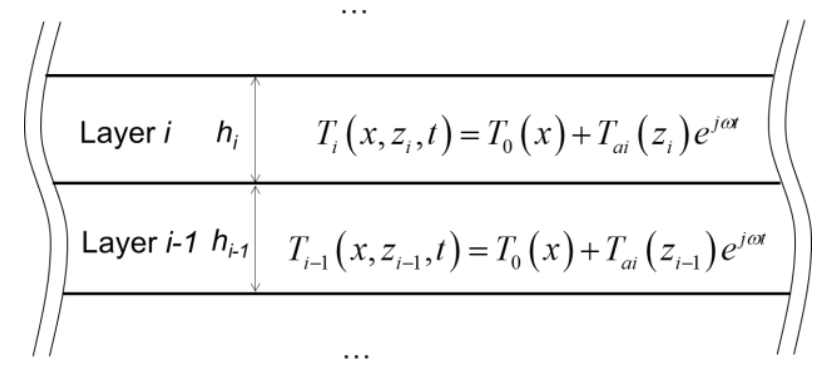

Figure 1: Configuration of the regenerative cooling system consisting of coplanar infinite layers of caloric material or fluid of thickness $h_{\text {. }}$.

\subsection{Heat transfer equations and solutions}

The thickness of the layers is along $\mathrm{z}$ axis. For each layer $i$, a dedicated $\mathrm{z}_{\mathrm{i}}$ coordinate is used, with $\mathrm{z}_{\mathrm{i}}=0$ at the center of the layer.

The following assumptions are used:

- Edge effect along y axis are neglected.

- In the heat transfer equation, variations along $\mathrm{z}$ axis are assumed to be larger and faster than that along $\mathrm{x}$ axis. This implies that the general expression of the temperature may be written as

$$
T_{i}\left(x, z_{i}, t\right)=T_{0}(x)+T_{a i}\left(z_{i}\right) e^{j \omega t}
$$


- The spatial temperature gradient along $\mathrm{x}$ axis is therefore identical for all layers, and varying very slowly compared to the excitation period $2 \pi / \omega$.

- Temperature and heat transfer along $\mathrm{z}$ axis are assumed to be continuous at the interface between two adjacent layers. Boundary condition therefore writes

$$
\begin{aligned}
& T_{i}\left(z_{i}=-\frac{h_{i}}{2}\right)=T_{i-1}\left(z_{i-1}=\frac{h_{i-1}}{2}\right) \\
& K_{i} \frac{\partial T_{i}\left(z_{i}=-\frac{h_{i}}{2}\right)}{\partial z_{i}}=K_{i-1} \frac{\partial T_{i-1}\left(z_{i-1}=\frac{h_{i-1}}{2}\right)}{\partial z_{i-1}}
\end{aligned}
$$

where $K_{i}$ is the thermal conductivity of layer $i$.

The general formulation of heat transfer equation in incompressible media is given by [46]

$$
T_{i}\left(\frac{\partial S_{i}}{\partial t}+\overrightarrow{v_{i}} \cdot \overrightarrow{\operatorname{grad}}\left(S_{i}\right)\right)=\operatorname{div}\left(K_{i} \cdot \overrightarrow{\operatorname{grad}}\left(T_{i}\right)\right)
$$

where $S_{i}$ is the local specific entropy of layer $i$.

Entropy variation $d S_{i}$ and heat exchanged $d Q_{i}$ of a layer i are given by

$$
d Q_{i}=T_{i} d S_{i}=d Q_{v o l_{-} i}+c_{i} d T_{i}
$$

where $d Q_{v o l_{-} i}$ is the internal volumetric heat source infinitesimal increment of layer $i$.

Assuming a homogenous and isotropic thermal conductivity, that the volume heat source is homogenous, and noticing that the motion of the material is along $\mathrm{x}$ axis only, the thermal equation yields [39] 
$c_{i}\left(\frac{\partial T_{i}}{\partial t}(t)+v_{i}(t) \frac{\partial T_{i}}{\partial x}(t)\right)+\frac{\partial Q_{i}}{\partial t}(t)=K_{i} \Delta T_{i}(t)$

In order to avoid a space discretization of the problem to be solved, it is chosen to search analytical solution of Eq. (7). Using the general expression of the temperature and motion (2) and (3), and using harmonic balance method (keeping only terms $e^{j \omega t}$ ) in $(7)$ :

$c_{i}\left(j \omega T_{a i}+v_{i} \frac{\partial T_{0}}{\partial x}\right)+j \omega q_{i}=K_{i} \frac{\partial^{2} T_{a i}}{\partial z_{i}^{2}}$

The partial derivative Eq. (8) includes static temperature gradient $\frac{\partial T_{0}}{\partial x}$ as an external parameter at this stage. The problem solving along $\mathrm{x}$-axis (cooling line direction) will link the net heat flux and the generated temperature gradient that results also from thermal boundary conditions (see section 3.3). Eq. (8) contains variation $T_{a i}$ and its second order derivative only, and the general solution is given by

$T_{a i}=A_{i} \cos k_{i} z_{i}+B_{i} \sin k_{i} z_{i}-\frac{q_{i}}{c_{i}}-\frac{v_{i}}{j \omega} \frac{\partial T_{0}}{\partial x}$

Where $k_{i}^{2}=-\frac{j \omega c_{i}}{K_{i}}=\left(\frac{1-j}{\delta_{i}}\right)^{2}, \delta_{i}=\sqrt{\frac{2 K_{i}}{\omega c_{i}}}$

being the thickness of the thermal boundary layer

Note that this general solution directly gives the distribution in space of the harmonic temperature variations.

The application of boundary conditions yields 


$$
\begin{aligned}
& A_{i} \cos \left(-k_{i} \frac{h_{i}}{2}\right)+B_{i} \sin \left(-k_{i} \frac{h_{i}}{2}\right)-\frac{q_{i}}{c_{i}}-\frac{v_{i}}{j \omega} \frac{\partial T_{0}}{\partial x} \\
& =A_{i-1} \cos \left(k_{i-1} \frac{h_{i-1}}{2}\right)+B_{i-1} \sin \left(k_{i-1} \frac{h_{i-1}}{2}\right)-\frac{q_{i-1}}{c_{i}}-\frac{v_{i-1}}{j \omega} \frac{\partial T_{0}}{\partial x} \\
& K_{i} k_{i}\left(-A_{i} \sin \left(-k_{i} \frac{h_{i}}{2}\right)+B_{i} \cos \left(-k_{i} \frac{h_{i}}{2}\right)\right) \\
& =K_{i-1} k_{i-1}\left(-A_{i-1} \sin \left(k_{i-1} \frac{h_{i-1}}{2}\right)+B_{i-1} \cos \left(k_{i-1} \frac{h_{i-1}}{2}\right)\right)
\end{aligned}
$$

For external layers (bottom and top locations along $\mathrm{z}$ axis), a Neumann condition is applied.

$$
\begin{aligned}
& K_{1} k_{1}\left(-A_{1} \sin \left(-k_{1} \frac{h_{1}}{2}\right)+B_{1} \cos \left(-k_{1} \frac{h_{1}}{2}\right)\right)=0 \\
& K_{N} k_{N}\left(-A_{N} \sin \left(k_{N} \frac{h_{N}}{2}\right)+B_{N} \cos \left(k_{N} \frac{h_{N}}{2}\right)\right)=0
\end{aligned}
$$

A system of $\mathrm{N}$ layers, consisting of $\mathrm{N}-1$ interfaces and 2 external layers results in $2 \mathrm{~N}$ equations $(2 *(\mathrm{~N}-1)+2)$. A matrix system was written for solving this linear equations system and determining amplitudes $A_{i}$ and $B_{i}$ for a given static temperature gradient $\frac{\partial T_{0}}{\partial x}$

From the amplitudes of the temperature variations in passive and active layers, it was computed the instantaneous heat flux along $\mathrm{x}$ axis per unit of surface

$$
\begin{aligned}
& p_{x}(t)=\operatorname{Re}\left\{v_{i} e^{j \omega t}\right\} \times \operatorname{Re}\left\{q_{i} e^{j \omega t}+c_{i} T_{0}+c_{i} T_{a i} e^{j \omega t}\right\} \\
& =\operatorname{Re}\left\{v_{i} e^{j \omega t}\right\} \times \operatorname{Re}\left\{q_{i} e^{j \omega t}+c_{i} T_{a i} e^{j \omega t}\right\}+\operatorname{Re}\left\{v_{i} e^{j \omega t}\right\} \times c_{i} T_{0}
\end{aligned}
$$

The second term of (13) being purely harmonic, its average over one period is null.

The averaging over one period of the left term is given by [47] 


$$
\left\langle p_{x}(t)\right\rangle=\frac{1}{2} \operatorname{Re}\left(\overline{v_{i}}\left(q_{i}+c_{i} T_{a i}\right)\right)
$$

The total heat flux (per unit of width, W. $\mathrm{m}^{-1}$ ) through the cross-section of the layers is

$$
P_{x}=\int_{0}^{t o t}\left\langle p_{x}(t)\right\rangle d z
$$

Note that Eq. (15) accounts for the hydrodynamic transport of the heat, resulting from the harmonic motion of the fluid, and from the heat conduction as well as fluid velocity whose exact profile is considered as known.

The maximum achievable temperature gradient along $\mathrm{x}$ axis may be estimated by setting a total heat flux along $\mathrm{x}$ axis to be zero, after adding the passive heat flux through the layers

$$
-\int_{t o t} K \frac{\partial T_{0}}{\partial x} d z+P_{x}=0
$$

\subsection{Example of result}

In these simulations, only three layers were considered. The properties set in the simulation are given in Table 1.

\begin{tabular}{|l|l|l|l|}
\hline Property & Symbol & Value & Unit \\
\hline Specific heat of natural rubber & $\mathrm{c}_{\text {rubber }}$ & $2 \times 10^{6}$ & $\mathrm{~J} \cdot \mathrm{m}^{-3} \cdot \mathrm{K}^{-1}$ \\
\hline Specific heat of fluid layer (water) & $\mathrm{c}_{\text {fluid }}$ & $4.18 \times 10^{6}$ & $\mathrm{~J} \cdot \mathrm{m}^{-3} \cdot \mathrm{K}^{-1}$ \\
\hline Thermal conductivity of natural rubber & $\mathrm{K}_{\text {rubber }}$ & 0.184 & $\mathrm{~W} \cdot \mathrm{m}^{-1} \cdot \mathrm{K}^{-1}$ \\
\hline Thermal conductivity of fluid layer (water) & $\mathrm{K}_{\text {fluid }}$ & 0.6 & $\mathrm{~W} \cdot \mathrm{m}^{-1} \cdot \mathrm{K}^{-1}$ \\
\hline Adiabatic temperature variation of natural rubber & $\Delta \mathrm{T}_{\mathrm{ad}}$ & 2 & ${ }^{\circ} \mathrm{C}$ \\
\hline
\end{tabular}




\begin{tabular}{|l|l|l|l|}
\hline Amplitude of fluid motion & $\mathrm{u}$ & 1 & $\mathrm{~cm}$ \\
\hline
\end{tabular}

Table 1 : Parameters used in the simulation of a three layers configuration

For each simulation, the static spatial temperature gradient along $\mathrm{x}$ axis was varied from $-2^{\circ} \mathrm{C} / \mathrm{cm}$ to $2^{\circ} \mathrm{C} / \mathrm{cm}$, in order to compute the net heat transfer along $\mathrm{x}$ axis as a function of the static spatial temperature gradient. The temperature amplitudes in each layer were first determined by the application of the boundary conditions. The amplitudes of Tai(z) are complex numbers, whose amplitude and phase is given by solving equation system (11) and (12). From these amplitudes, the net heat flux along $\mathrm{x}$ axis is calculated by the integral given in Eq. (14) and (15).
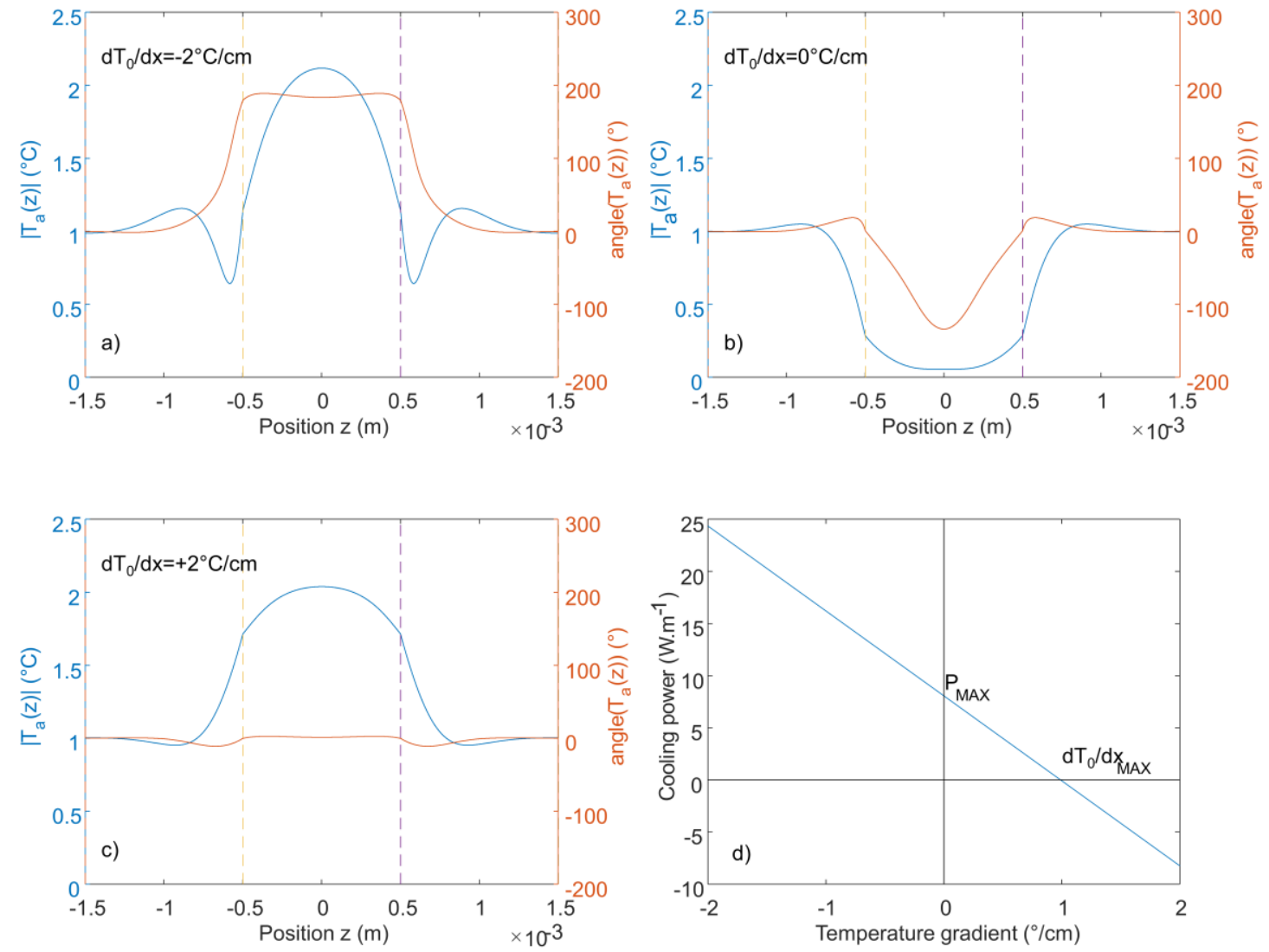

Figure 2: Typical result of the simulation for a $1 \mathrm{~Hz}$ excitation and $1 \mathrm{~mm}$ fluid layer thickness: a) amplitude and phase of the temperature variations for both rubber (located $-1.5 \mathrm{~mm}<z<-0.5 \mathrm{~mm}$ and $0.5 \mathrm{~mm}>z>1.5 \mathrm{~mm}$ ) and fluid (located $-0.5 \mathrm{~mm}>z>0.5 \mathrm{~mm}$ ), and for a temperature gradient of $-2^{\circ} \mathrm{C} / \mathrm{cm}, \mathrm{b}$ ) for $0 \% \mathrm{~cm}$ and c) for $+2{ }^{\circ} \mathrm{C} / \mathrm{cm}$. In d), the overall heat flux (per unit of width) is plotted against the temperature gradient, thus highlighting the maximum heat flux (for null temperature gradient), and the maximal temperature gradient fort when the heat flux becomes null. The slope of this curve corresponds to the effect of the thermal conductivity. 
In Figure 2 is shown a typical result for a $1 \mathrm{~Hz}$ excitation and a fluid and rubber thickness of $1 \mathrm{~mm}$. The temperature variation amplitude profile is shown for different temperature gradients, and the resulting plot of total heat flux versus gradient $\frac{\partial T_{0}}{\partial x}$ is given. The space variable $\mathrm{z}$ refers to the axis perpendicular to the rubber and fluid layers. The motion of fluid is along $\mathrm{x}$ axis. The fluid is between two rubber layers, and the outer surface of rubber layers are located at $\mathrm{z}=1.5 \mathrm{~mm}$ and $\mathrm{z}=-1.5 \mathrm{~mm}$. In the simulation, the adiabatic temperature change of the rubber was set to $2^{\circ} \mathrm{C}$, that is to say $1{ }^{\circ} \mathrm{C}$ harmonic amplitude. This temperature amplitude is naturally found on the external edges of the rubber, which are not or weakly influenced by the fluid motion. On the contrary, close to this boundary (at $\mathrm{z}=-0.5 \mathrm{~mm}$ and $\mathrm{z}=0.5 \mathrm{~mm}$ ), the fluid temperature variations generate additional temperature variation in the rubber as the result of the heat conduction and the continuity of temperature and heat flow at the interface. The fluid temperature variations have two origins. The first one is the temperature spatial gradient $\frac{\partial T_{0}}{\partial x}$ multiplied by the harmonic displacement of the fluid, resulting in time variations at a fixed location $\mathrm{x}$ of the cooling line. It should be noted that the phase of the fluid layer temperature variation is naturally reversed when the temperature gradient has an opposite sign. The second origin of the fluid temperature variation is the influence of the rubber layer exhibiting elastocaloric effect. At zero gradient $\frac{\partial T_{0}}{\partial x}$, the temperature variation of the fluid is solely due to the rubber temperature variations. It is confined near the interface (i.e. a few hundreds of micrometers), consistently to the thermal boundary layer thickness $\delta_{i}=\sqrt{\frac{2 K_{i}}{\omega c_{i}}}$ in the fluid.

By integrating the temperature variation of the fluid by its velocity (Eq. (14), (15), (16)), it was calculated the resulting net heat flux, which of course depends on the 
temperature gradient $\frac{\partial T_{0}}{\partial x}$. In the absence of elastocaloric effect, the slope would be decreasing and crossing the origin of the graph heat flux versus temperature gradient. Indeed, when the temperature gradient is positive, heat flux appears towards decreasing $\mathrm{x}$ coordinate. The elastocaloric effect combined with the fluid motion results in a net heat flux along x direction (Eq. (16)), and hence in a translation of the total heat flux. The quarter with positive temperature gradient and heat flux may be seen as the heat engine characteristic: without temperature gradient the heat flux is maximum, and the heat flux vanishes when the cooling power is totally counterbalanced by the heat conduction along $\mathrm{x}$ axis.

In a second step, the influence of the total number of layers was investigated ( $\mathrm{N}$ layers of fluid and $\mathrm{N}+1$ layers of rubber). The total number of layers $(2 \mathrm{~N}+1)$ is varied between 3 and $3 \times 10^{3}$. For the sake of comparison, the cooling power is normalized with regards of the total thickness of the layered system, thus leading to a surface power $\left(\mathrm{W} \cdot \mathrm{m}^{-2}\right)$. Parameters are the same as in Table 1, thickness of the layers are all $1 \mathrm{~mm}$, and the frequency is set to $1 \mathrm{~Hz}$.

As shown in Figure 3, both surface power and temperature gradient reaches a plateau from about $~ 50$ layers (i.e 25 layers of rubber and 24 layers of fluid). The temperature gradient is almost the same for all tested number of layers, whereas the cooling power increases quickly and reaches $90 \%$ of its maximum from 10 layers. From a large number of layers, all of them exhibit very close temperature variations. In this case, the edge effects on the two outer layers becomes negligible, and this result serves as a basis of further simplification of the problem as shown hereafter. 


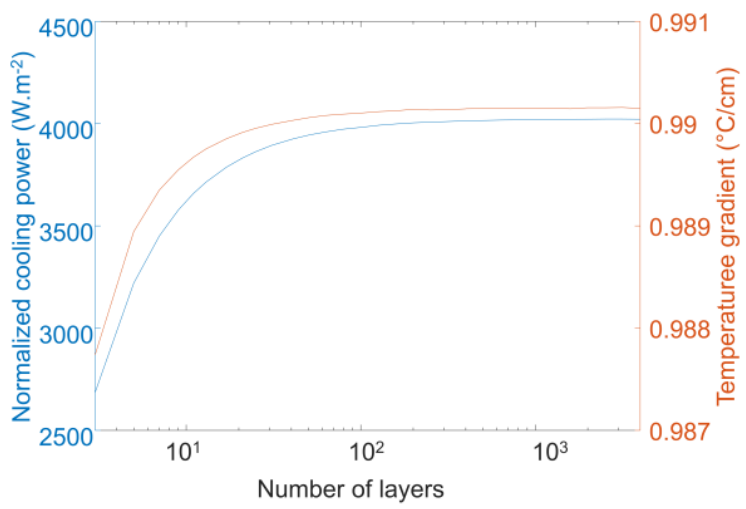

Figure 3 : Effect of the total number of layers of fluid and elastocaloric material on the cooling power and maximum temperature gradient

\subsection{Model for an infinite repetition of rubber / fluid layering}

The model was then defined as two layers (one of rubber, one of fluid), where the boundary conditions are set so that the upper layer have thermal exchange with a virtuous layer identical to the bottom one. The layer ' 1 ' is the rubber one, subjected to a heat source $\mathrm{q}_{1}$ and no motion $\left(\mathrm{v}_{1}=0\right)$, whereas the second layer is made of fluid, without heat source $\left(\mathrm{q}_{2}=0\right)$, but subjected to speed along $\mathrm{x}$ of speed $\mathrm{v}_{2}$.

It should be noted that the assumption of a homogeneous flow is not realistic, and is used up to this point as a way to keep analytical solutions. It should be noted that in section 3.2 the influence of inhomogeneous flow will be discussed. The error introduced by the consideration of a homogeneous flow is not negligible and lead eventually to an overestimation of a factor two on the cooling power. Nevertheless, it is considered that the tendencies are kept, and that the figures of merit from the elastocaloric material point of view remain valid.

The continuity of temperature and heat flux is ensured at the middle interface $\left(\mathrm{z}_{1}=\mathrm{h}_{1} / 2\right.$ for layer ' 1 ', corresponding to $\mathrm{z}_{2}=-\mathrm{h}_{2} / 2$ for layer ' 2 '). In addition, the lower surface of layer ' 1 ' $\left(\mathrm{z}_{1}=-\mathrm{h}_{1} / 2\right)$ is considered in contact with the upper surface of layer ' 2 ' $\left(\mathrm{z}_{2}=\mathrm{h}_{2} / 2\right)$, thus simulating the infinite repetition of layers. 
Equation system therefore writes

$$
\left[\begin{array}{cccc}
\cos \left(k_{1} \frac{h_{1}}{2}\right) & \sin \left(k_{1} \frac{h_{1}}{2}\right) & -\cos \left(-k_{2} \frac{h_{2}}{2}\right) & -\sin \left(-k_{2} \frac{h_{2}}{2}\right) \\
-K_{1} k_{1} \sin \left(k_{1} \frac{h_{1}}{2}\right) & K_{1} k_{1} \cos \left(k_{1} \frac{h_{1}}{2}\right) & K_{2} k_{2} \sin \left(-k_{2} \frac{h_{2}}{2}\right) & -K_{2} k_{2} \cos \left(-k_{2} \frac{h_{2}}{2}\right) \\
\cos \left(-k_{1} \frac{h_{1}}{2}\right) & \sin \left(-k_{1} \frac{h_{1}}{2}\right) & -\cos \left(k_{2} \frac{h_{2}}{2}\right) & -\sin \left(k_{2} \frac{h_{2}}{2}\right) \\
-K_{1} k_{1} \sin \left(-k_{1} \frac{h_{1}}{2}\right) & K_{1} k_{1} \cos \left(-k_{1} \frac{h_{1}}{2}\right) & K_{2} k_{2} \sin \left(k_{2} \frac{h_{2}}{2}\right) & -K_{2} k_{2} \cos \left(k_{2} \frac{h_{2}}{2}\right)
\end{array}\right] \times\left[\begin{array}{c}
A_{1} \\
B_{1} \\
A_{2} \\
B_{2}
\end{array}\right]=\left[\begin{array}{c}
\frac{q_{1}}{c_{1}}-\frac{v_{2}}{j \omega} \frac{\partial T_{0}}{\partial x} \\
0 \\
\frac{q_{1}}{c_{1}}-\frac{v_{2}}{j \omega} \frac{\partial T_{0}}{\partial x} \\
0
\end{array}\right]
$$

Solving the equation system leads to

$$
\begin{aligned}
& A_{1}=\frac{\frac{q_{1}}{c_{1}}-\frac{v_{2}}{j \omega} \frac{\partial T_{0}}{\partial x}}{\cos \left(k_{1} \frac{h_{1}}{2}\right)+\frac{K_{1} k_{1} \sin \left(k_{1} \frac{h_{1}}{2}\right)}{K_{2} k_{2} \sin \left(k_{2} \frac{h_{2}}{2}\right)} \cos \left(k_{2} \frac{h_{2}}{2}\right)} \\
& A_{2}=\frac{-\frac{q_{1}}{c_{1}}+\frac{v_{2}}{j \omega} \frac{\partial T_{0}}{\partial x}}{\cos \left(k_{2} \frac{h_{2}}{2}\right)+\frac{K_{2} k_{2} \sin \left(k_{2} \frac{h_{2}}{2}\right)}{K_{1} k_{1} \sin \left(k_{1} \frac{h_{1}}{2}\right)} \cos \left(k_{1} \frac{h_{1}}{2}\right)}
\end{aligned}
$$

$B_{1}=B_{2}=0$

Using (14), and noticing that only fluid layer ('2') can lead to a non-zero heat flux, the time average heat flux along $\mathrm{x}$ axis yields

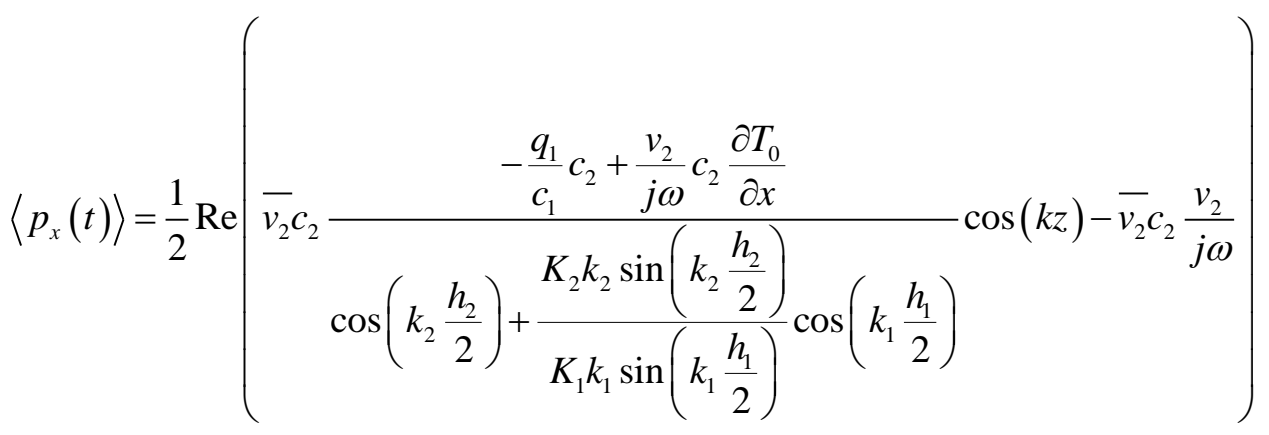

Considering that the last term on the right hand is purely imaginary, and integrating along the thickness of layer 2 between $-h_{2} / 2$ and $h_{2} / 2$ : 


$$
P_{x}=\int_{-\frac{h_{2}}{2}}^{\frac{h_{2}}{2}}\left\langle p_{x}(t)\right\rangle d z_{2}=\operatorname{Re}\left(\frac{-\frac{q_{1}}{c_{1}} \overline{v_{2}} c_{2}+\frac{\left|v_{2}\right|^{2}}{j \omega} c_{2} \frac{\partial T_{0}}{\partial x}}{\frac{\cos \left(k_{2} \frac{h_{2}}{2}\right)}{\sin \left(k_{2} \frac{h_{2}}{2}\right)}+\frac{K_{2} k_{2} \cos \left(k_{1} \frac{h_{1}}{2}\right)}{K_{1} k_{1} \sin \left(k_{1} \frac{h_{1}}{2}\right)}}\right)
$$

In Eq. (20), when the thickness of the rubber and fluid layers are much smaller compared to the corresponding thermal boundary layers, $\tan \left(k \frac{h}{2}\right)=\tan \left(\frac{1-j}{\delta} \frac{h}{2}\right) \stackrel{\delta \gg h}{\rightarrow} \frac{h}{2 \delta}(1-j)$, and the power tends to zero.

Alternatively, the thicknesses of the layers were then assumed to be much larger than the thermal boundary layer thicknesses $\delta$,

$$
\tan \left(k \frac{h}{2}\right)=\tan \left(\frac{1-j}{\delta} \frac{h}{2}\right) \stackrel{h>>\delta}{\rightarrow} \frac{1}{j}
$$

Writing $k_{2}=\frac{1-j}{\delta_{2}}$ and $\frac{K_{2} k_{2}}{K_{1} k_{1}}=\sqrt{\frac{K_{2} c_{2}}{K_{1} c_{1}}}$,

$$
P_{x}=\operatorname{Re}\left(\frac{j \frac{q_{1}}{c_{1}} \bar{v}_{2} c_{2}}{1+\sqrt{\frac{K_{2} c_{2}}{K_{1} c_{1}}}} \frac{\delta_{2}}{1-j}\right)-\operatorname{Re}\left(\frac{\frac{\left|v_{2}\right|^{2}}{\omega} c_{2} \frac{\partial T_{0}}{\partial x}}{1+\sqrt{\frac{K_{2} c_{2}}{K_{1} c_{1}}}} \frac{\delta_{2}}{1-j}\right)
$$

The speed of the fluid layer is a complex number, function of the phase shift between motion of the fluid compared to the excitation of the caloric effect. The fluid layer is subjected to a displacement written $u_{2}(t)=u_{0} e^{j \varphi} e^{j \omega t}$, its speed is then written $v_{2}(t)=j \omega u_{0} e^{j \varphi} e^{j \omega t}=j v_{0} e^{j \varphi} e^{j \omega t}$, thus $\overline{v_{2}}=v_{0} e^{-j\left(\varphi+\frac{\pi}{2}\right)}$. The expression of the cooling power further simply into 


$$
P_{x}=\frac{q_{1} v_{0} c_{2} \delta_{2}}{1+\sqrt{\frac{K_{2} c_{2}}{K_{1} c_{1}}}} \frac{\cos \varphi+\sin \varphi}{2 c_{1}}-\frac{v_{0}{ }^{2}}{1+\sqrt{\frac{K_{2} c_{2}}{K_{1} c_{1}}}} \frac{c_{2} \delta_{2}}{2 \omega} \frac{\partial T_{0}}{\partial x}
$$

It is rewritten as

$$
P_{x}=\left(h_{1}+h_{2}\right)\left(P_{0}-K_{\text {active }} \frac{\partial T_{0}}{\partial x}\right)
$$

With $P_{0}=\frac{q_{1} v_{0} c_{2} \delta_{2}}{1+\sqrt{\frac{K_{2} c_{2}}{K_{1} c_{1}}}} \frac{\cos \varphi+\sin \varphi}{2 c_{1}\left(h_{1}+h_{2}\right)}$

and $K_{\text {active }}=\frac{v_{0}{ }^{2}}{1+\sqrt{\frac{K_{2} c_{2}}{K_{1} c_{1}}}} \frac{c_{2} \delta_{2}}{2 \omega\left(h_{1}+h_{2}\right)}$

$P_{0}$ the surface cooling power generated by the system over all the layers, and $K_{\text {active }}$ is a thermal conductivity resulting from the motion of the fluid.

Using (16), the maximal temperature gradient is given by

$$
\left.\frac{\partial T_{0}}{\partial x}\right|_{\text {MAX }}=\frac{P_{0}}{K_{\text {active }}+\left(\frac{K_{1} h_{1}+K_{2} h_{2}}{h_{1}+h_{2}}\right)}
$$

\subsection{Parametric study of the regenerative system performance}

In the following simulations, different fluid thicknesses were tested for $0.1 \mathrm{~Hz}$ and $1 \mathrm{~Hz}$ excitations with a phase shift $\varphi=0$. In Figure 4 are shown the results for both frequencies and for different fluid layer thicknesses. It appeared that an optimal fluid layer thickness exists. A larger thickness maximizes the total cooling power reaching a plateau, but as the thickness increases, the surface cooling power $P_{0}$ decreases. However, the temperature gradient decreases quickly due to the higher passive heat conduction in the fluid layer. The performances are kept close to maximum for a wide range of thicknesses (between $300 \mu \mathrm{m}$ and $3 \mathrm{~mm}$ ). Finally, increase of the frequency decreases the value of the optimal fluid layer thickness, in agreement with the decrease 
of the thermal boundary layer thickness. The cooling power however increases significantly with the frequency.

Unsurprisingly, the analytical approximation is very accurate for very large thickness, where the assumption $\mathrm{h} \gg>\delta$ is reasonable. Below $1 \mathrm{~mm}$, the thermal boundary layer thickness is closer to the fluid layer thickness, or even larger. Therefore, the analytical approximation is unable to catch the optimum layer thickness. Nevertheless, it is shown that from $1 \mathrm{~mm}$ and above, the accuracy of the analytical approximation is rather good. It was also observed that changing the thickness of rubber layer resulted in very similar results.

In Table 2 are given the set of properties used for checking the effect of fluid thermal conductivity.

\begin{tabular}{|l|l|l|l|}
\hline Property & Symbol & Value & Unit \\
\hline Specific heat of natural rubber & crubber & $2 \times 10^{6}$ & $\mathrm{~J} \cdot \mathrm{m}^{-3} \cdot \mathrm{K}^{-1}$ \\
\hline Specific heat of fluid layer & $\mathrm{c}_{\text {fluid }}$ & $4.18 \times 10^{6}$ & $\mathrm{~J} \cdot \mathrm{m}^{-3} \cdot \mathrm{K}^{-1}$ \\
\hline Thermal conductivity of natural rubber & $\mathrm{K}_{\text {rubber }}$ & 0.184 & $\mathrm{~W} \cdot \mathrm{m}^{-1} \cdot \mathrm{K}^{-1}$ \\
\hline Thermal conductivity of fluid layer & $\mathrm{K}_{\text {fluid }}$ & $10^{-2} \sim 10^{1}$ & $\mathrm{~W} \cdot \mathrm{m}^{-1} \cdot \mathrm{K}^{-1}$ \\
\hline Adiabatic temperature variation of natural rubber & $\Delta \mathrm{T}_{\text {ad }}$ & 2 & ${ }^{\circ} \mathrm{C}$ \\
\hline Amplitude of fluid motion & $\mathrm{u}$ & 1 & $\mathrm{~cm}$ \\
\hline Layers thickness (both rubber and fluid) & $\mathrm{h}$ & 1 & $\mathrm{~mm}$ \\
\hline Frequency of excitation & $\mathrm{f}$ & 1 & $\mathrm{~Hz}$ \\
\hline Phase shift & $\varphi$ & 0 & $\mathrm{rad}$ \\
\hline
\end{tabular}



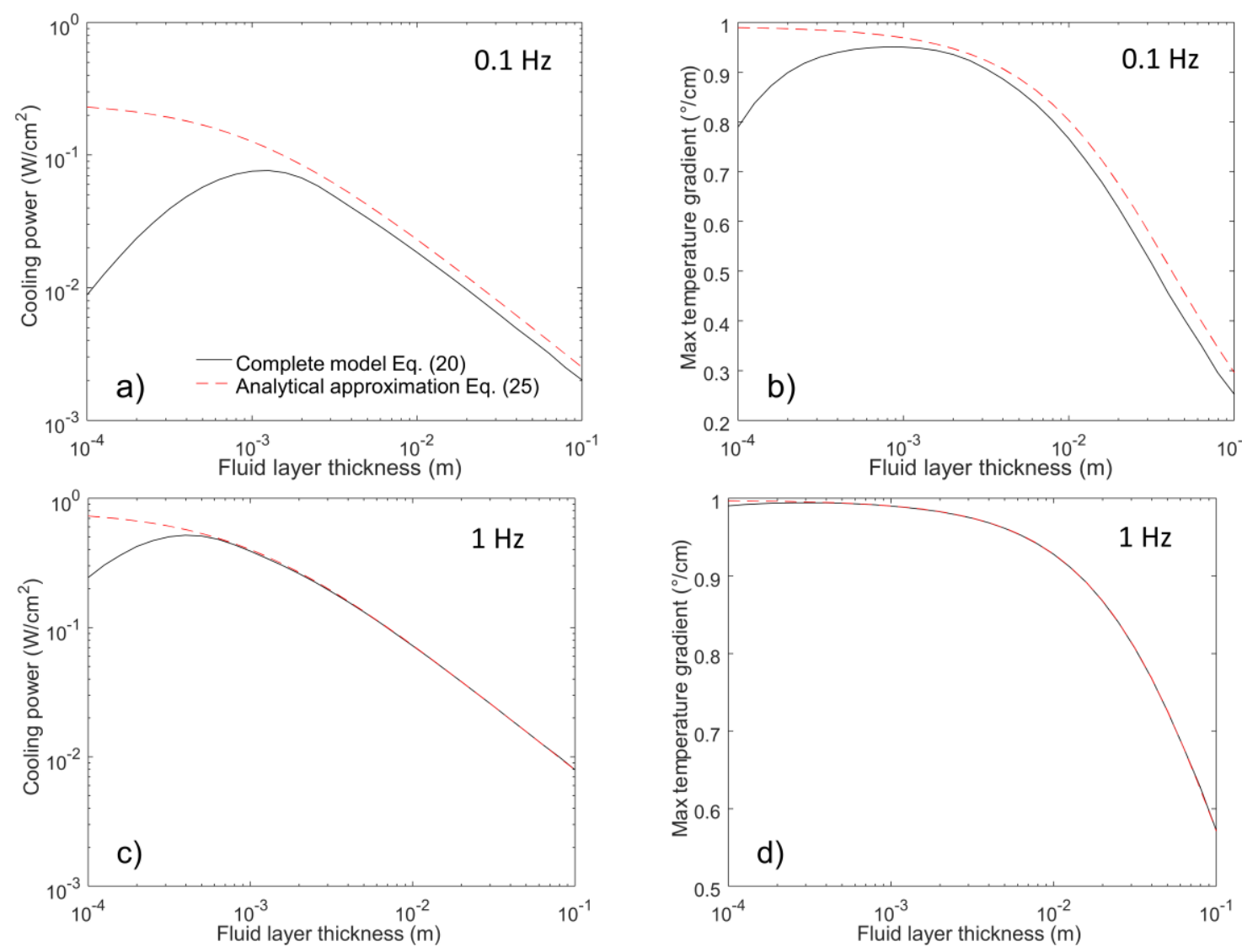

Figure 4 : Effect of the thickness of fluid layer on cooling performances at $0.1 \mathrm{~Hz}:$ a) surface cooling power and b) maximal temperature gradient along $x$ axis. For a frequency of $1 \mathrm{~Hz}:$ c) surface cooling power and d) maximal temperature gradient. On each graph, the black curve is obtained using Eq. (20) (no assumption on the layers thicknesses), whereas dotted red line is resulting from Eq. (25) (layers thicknesses much larger than the thermal boundary layer thickness).
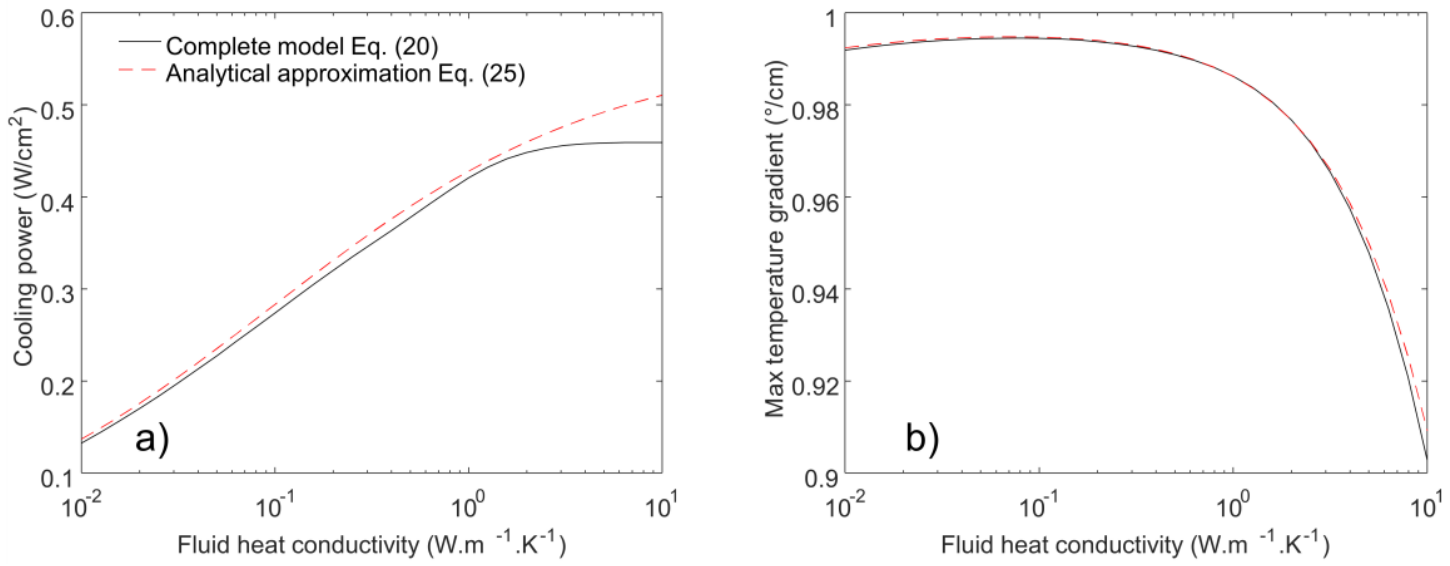

Figure 5 : Effect of thermal conductivity of fluid layer on the cooling power (a) and on the temperature gradient (b)

In Figure 5 are shown the main results. The cooling power increases significantly with the thermal conductivity while the temperature gradient remains almost constant. Above $3 \mathrm{~W} \cdot \mathrm{m}^{-1} \cdot \mathrm{K}^{-1}$, a plateau is reached for the cooling power, because the thermal boundary layer thickness becomes too close to the thickness of the layer (for $3 \mathrm{~W} \cdot \mathrm{m}^{-1} \cdot \mathrm{K}^{-1}$, 
$\delta \sim 500 \mu \mathrm{m})$.

From the previous simulations, it is noticeable that geometry of the system can be adjusted according to the properties of the materials, in order to obtain a good matching between thermal boundary layer and layers thicknesses.

\subsection{Towards an elastocaloric figure of merit}

The analytical solution given in (25) was further simplified in order to be able to catch a relevant combination of both active and passive materials properties. From the expression of cooling power (27), the terms related to active and passive heat conductivities were compared for $1 \mathrm{~Hz}$ excitation and a displacement of fluid of $1 \mathrm{~cm}$. Heat capacity were taken from Table 2. In Figure 6 is shown the comparison between active and passive heat conductivities, where both rubber and fluid layers heat conductivities are identical and varied between $10^{-2}$ and $10^{1} \mathrm{~W} \cdot \mathrm{m}^{-1} \cdot \mathrm{K}^{-1}$. Although the motion of fluid is rather small $(1 \mathrm{~cm})$, it is found that the active thermal conductivity is always much larger than that of passive layers, with at least one decade higher value even for a passive thermal conductivity of $10 \mathrm{~W} \cdot \mathrm{m}^{-1} \cdot \mathrm{K}^{-1}$.

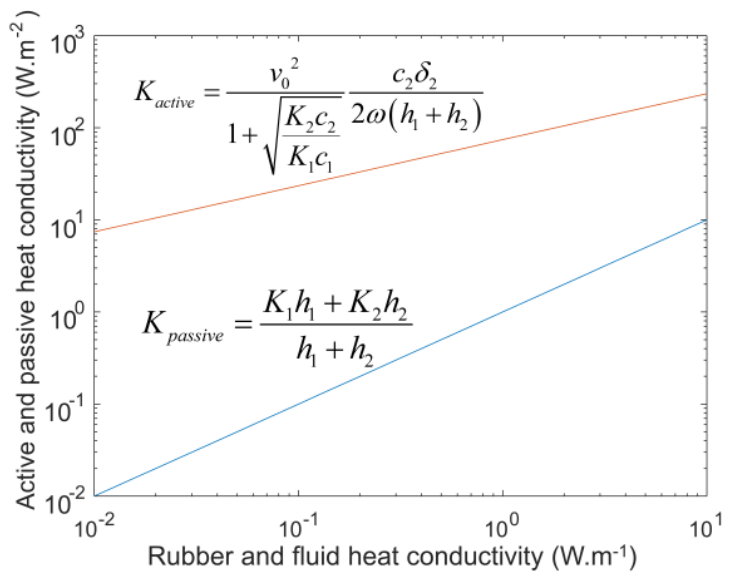

Figure 6 : Comparison between active and passive heat conductivities in case of an infinite repetition of elastocaloric material layer and fluid layer

The surface cooling power and temperature gradient were then simplified neglecting passive thermal conductivity with regard to the active one. In addition, in the view of 
defining a figure of merit, the phase shift between excitation of the caloric effect and fluid motion is set to zero. Finally, recalling that the adiabatic temperature change of rubber writes $\Delta T_{a d}=2 \frac{q_{1}}{c_{1}}$, and that the fluid displacement amplitude is $u_{0}=\frac{v_{0}}{\omega}$, the expressions simplifies into

$$
P_{0}=\frac{\Delta T_{a d} u_{0} \sqrt{2 K_{2} c_{2} \omega}}{4\left(1+\sqrt{\frac{K_{2} c_{2}}{K_{1} c_{1}}}\right)\left(h_{1}+h_{2}\right)}
$$

The temperature gradient is given by

$$
\left.\frac{\partial T_{0}}{\partial x}\right|_{M A X} \approx \frac{\Delta T_{a d}}{2 u_{0}}
$$

The previous simplified results are compared to non-simplified model in Figure 7.
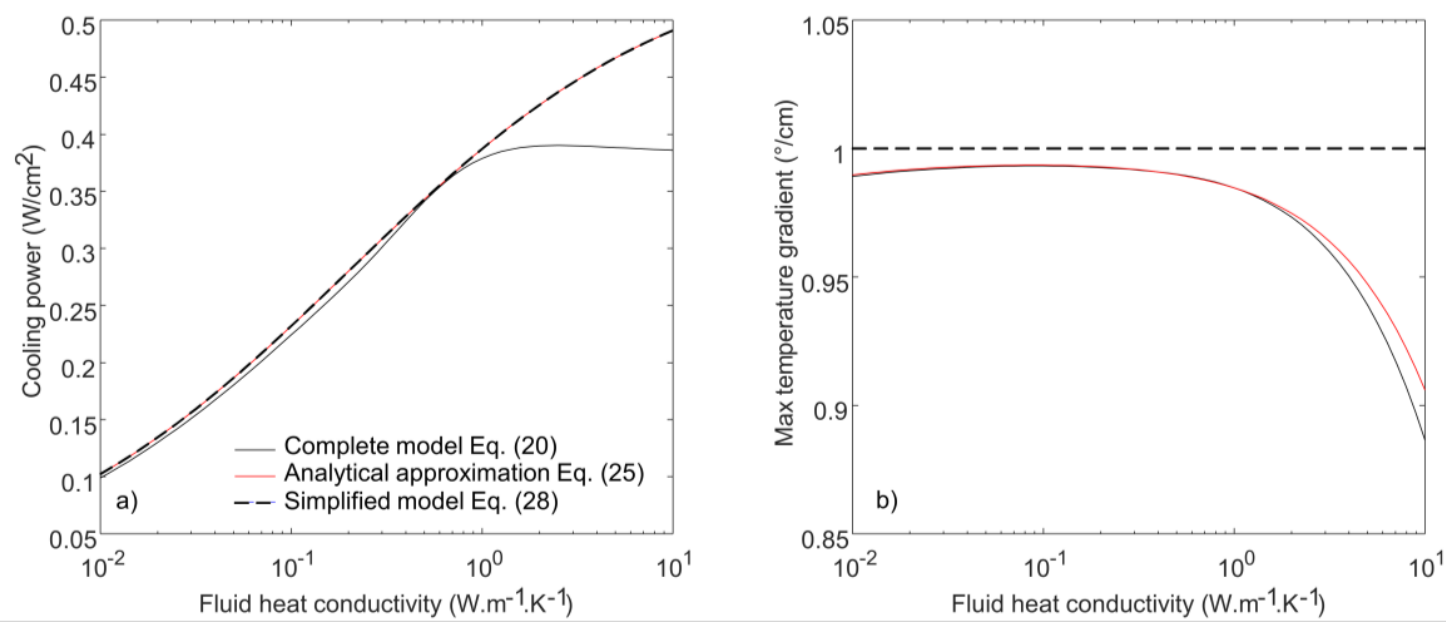

Figure 7: Comparison between simplified expressions and complete model in case of an infinite repetition of elastocaloric material layer and fluid layer

From these results, the following conclusions have been drawn:

- Under these assumptions, the temperature gradient amplitude is directly given by the adiabatic temperature change divided by the fluid displacement.

- From the expression of cooling power given in (28), a clear figure of merit can be hardly obtained. The limiting factor is a combination of passive and active 
layers. Two limit cases are tested:

$\circ \frac{K_{2} c_{2}}{K_{1} c_{1}} \gg>1$ (rubber layer is much less conductive than fluid layer). The cooling power then simplifies into $P_{0}=\frac{\Delta T_{a d} u_{0} \sqrt{2 K_{1} c_{1} \omega}}{4\left(h_{1}+h_{2}\right)}$, and the rubber figure of merit is $F O M_{\text {rubber }}=\Delta T_{a d} \sqrt{2 K_{1} c_{1}}$

$\circ \frac{K_{2} c_{2}}{K_{1} c_{1}} \ll<1$ (rubber layer is much more conductive than fluid one). The cooling power then simplifies into $P_{0}=\frac{\Delta T_{a d} u_{0} \sqrt{2 K_{2} c_{2} \omega}}{4\left(h_{1}+h_{2}\right)}$, and the figure of merit combines both rubber and fluid properties $F O M_{\text {fluid }}=\Delta T_{a d} \sqrt{2 K_{2} c_{2}}$

The results presented above suggest that the limiting factor in terms of cooling power is given by either the caloric material or the fluid. Increasing both heat capacity and thermal conductivity have beneficial effects. However, one should keep in mind that the thickness of the layers should be larger than the thermal boundary layer thickness in each type of material, which add constraints on the frequency of operation. Considering water as working fluid and natural rubber, and their thermal properties, the thermal boundary layer range is between $600 \mu \mathrm{m} @ 0.1 \mathrm{~Hz}$ and $200 \mu \mathrm{m} @ 1 \mathrm{~Hz}$ for both. Such thickness is compatible with practical constraints in term of geometrical design of a cooling device.

Replacing natural rubber by shape-memory alloy (such as NiTi alloy exhibiting very large elastocaloric activity [48]) would allow larger thickness of active material (up to a few $\mathrm{mm}$ ), while the performance will remain limited by that of working fluid. 


\section{Model for complex geometries}

The previous conclusions needed to be confirmed by the validation of the model through comparison with experimental result. The rather simple geometry presented previously was however impractical for experimental testing, and a cylindrical geometry was preferred. The model was therefore adapted to an axisymmetric configuration.

\subsection{Cylindrical geometries}

It was considered a system composed on concentric tubes of elastocaloric material or fluid moving along the axis of the tubes.

Compared to the planar case solved previously, equation (8) is modified as

$c_{i}\left(j \omega T_{a i}+v_{i} \frac{\partial T_{0}}{\partial x}\right)+j \omega q_{i}=\frac{K_{i}}{r} \frac{\partial T_{a i}}{\partial r}+K_{i} \frac{\partial^{2} T_{a i}}{\partial r^{2}}$

The solution is given by Bessel functions:

$T_{a i}(r)=A_{i} J_{0}\left(k_{i} r\right)+B Y_{0}\left(k_{i} r\right)-\frac{v_{i}}{j \omega} \frac{\partial T_{0}}{\partial x}-\frac{q_{i}}{c_{i}}$

where $J_{0}$ and $Y_{0}$ are Bessel's function of first kind and second kind of $0^{\text {th }}$ order respectively, and where $k_{i}^{2}=-\frac{j \omega c_{i}}{K_{i}}=\left(\frac{1-j}{\delta_{i}}\right)^{2}, \delta_{i}=\sqrt{\frac{2 K_{i}}{\omega c_{i}}}, \delta_{i}$ being the thickness of the thermal boundary layer.

The application of boundary conditions, at the interface between two tubes at radius $r_{i-1}$, yields 


$$
\begin{aligned}
& A_{i} J_{0}\left(k_{i} r_{i-1}\right)+B_{i} Y_{0}\left(k_{i} r_{i-1}\right)-\frac{q_{i}}{c_{i}}-\frac{v_{i}}{j \omega} \frac{\partial T_{0}}{\partial x} \\
& =A_{i-1} J_{0}\left(k_{i-1} r_{i-1}\right)+B_{i-1} Y_{0}\left(k_{i-1} r_{i-1}\right)-\frac{q_{i-1}}{c_{i}}-\frac{v_{i-1}}{j \omega} \frac{\partial T_{0}}{\partial x} \\
& K_{i} k_{i}\left(A_{i} J_{1}\left(k_{i} r_{i-1}\right)+B_{i} Y_{1}\left(k_{i} r_{i-1}\right)\right) \\
& =K_{i-1} k_{i-1}\left(A_{i-1} J_{1}\left(k_{i-1} r_{i-1}\right)+B_{i-1} Y_{1}\left(k_{i-1} r_{i-1}\right)\right)
\end{aligned}
$$

where $J_{l}$ and $Y_{l}$ are Bessel's function of first kind and second kind of $1^{\text {st }}$ order respectively

For the cylindrical tube at the center, as well at the outer tube, the conditions write

$$
\begin{aligned}
& B_{1}=0 \\
& A_{N} J_{1}\left(k_{N} r_{N}\right)+B_{N} Y_{1}\left(k_{N} r_{N}\right)=0
\end{aligned}
$$

Similarly to the planar case, the boundary conditions lead to a set of $2 \mathrm{~N}$ linear equations and $2 \mathrm{~N}$ amplitudes to be determined.

From the knowledge of the temperature variation amplitudes, the cooling power was computed by integrating the heat flux along the radius, and by summing on all the considered layers. Recalling that the local mean heat flux along $\mathrm{x}$-axis is given by $\left\langle p_{x}(t)\right\rangle=\frac{1}{2} \operatorname{Re}\left(\overline{v_{i}}\left(q_{i}+c_{i} T_{a i}\right)\right)$, the total cooling power writes

$$
P_{x}=\sum_{i=0}^{i=N-1} \int_{r_{i}}^{r_{i+1}}\left\langle p_{x}(t)\right\rangle 2 \pi r d r
$$

The calculation of temperature variations amplitudes (Eq. (32) and (33)) was done for different static temperature gradient amplitudes. After the calculation of the cooling power, the power versus temperature gradient is obtained (similarly to Figure 2d). From this result, the cooling power $P_{M A X}$ and the equivalent active thermal conductivity $K_{\text {active }}$ (given by the slope of the curve) was deduced. 


\subsection{Inhomogeneous fluid motion}

As the motion profile of the fluid is not homogeneous inside the tube, it was assumed to be given by a Poiseuille flow. Therefore, the velocity front is parabolic, with a speed being nill at the contact with the elastocaloric material. For simulation purposes, the inner tube was divided into $\mathrm{N}$ concentric tubes, all made of fluid with different speed profiles in order to reconstruct the Poiseuille flow. An example with $\mathrm{N}=9$ is given in Figure 8a. In subsequent simulations, $\mathrm{N}=150$ was preferred in order to have a continuous fluid velocity profile.

In terms of cooling performance, it should be noted from Eq. (14) that cooling power is given by the product of the fluid speed by its cyclic temperature variations. The speed of the fluid is maximum at the center of the tube in case of a Poiseuille flow, where the temperature variations are the lowest. As a consequence, the output power is decreased significantly for low values of fluid thermal conductivity. A comparison between Poiseuille flow and a homogeneous speed flow is given in Figure 8b. For larger thermal conductivity, it should be noted that an inhomogeneous flow gives slightly higher cooling power. In this case, the thermal boundary layer is larger than the diameter of the tube, and if the cooling power is a nonlinear function of the speed of the fluid, it can lead to a higher value compared to a homogeneous flow case. In any case, the drastically increased active thermal conductivity is responsible for a decrease by a factor of 2 of the maximum achievable temperature gradient as shown in Figure 8c. 

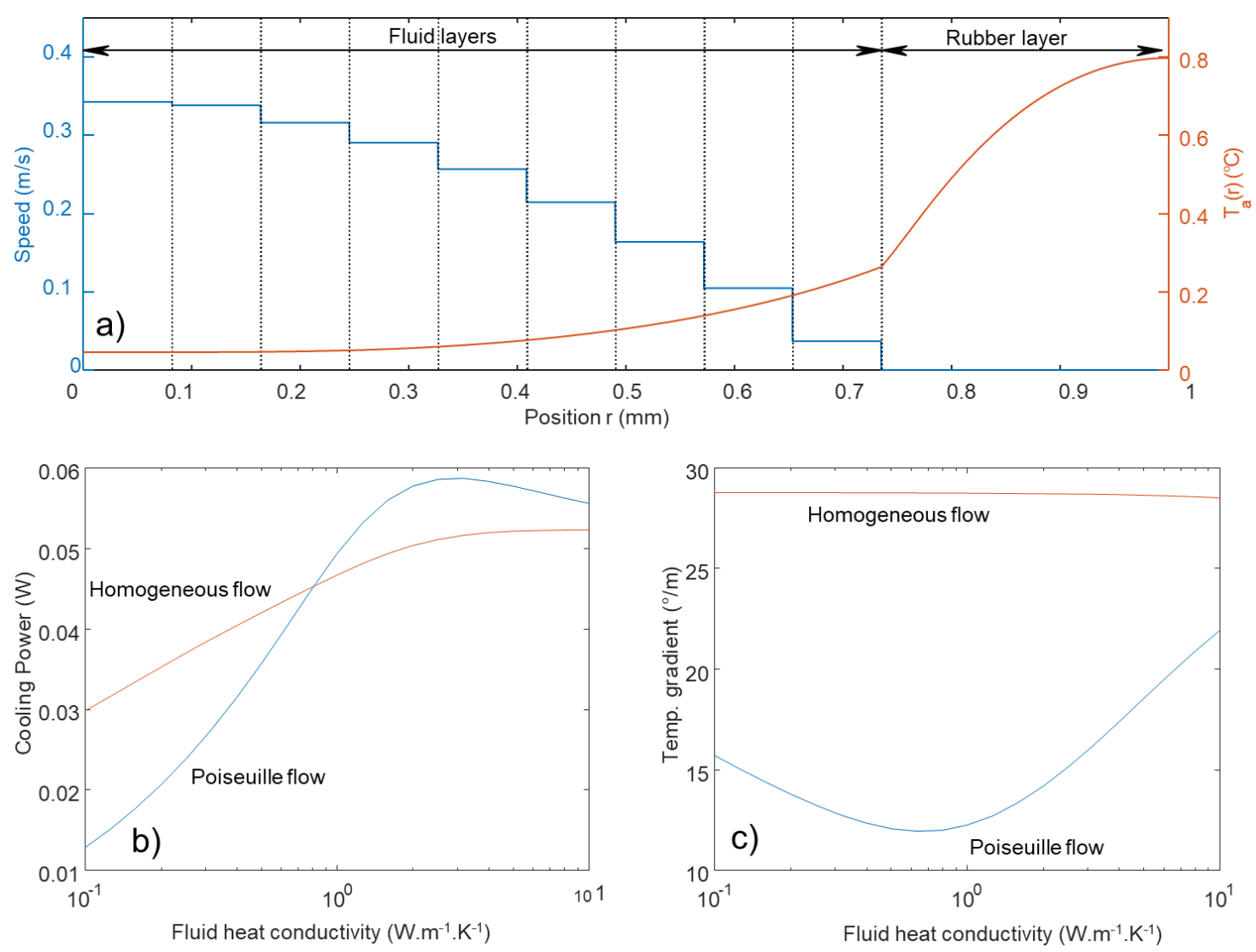

Figure 8: Simulation of Poiseuille flow using successive concentric tubes of fluid at different speeds. a) Resulting speed and temperature variation amplitude. The comparison between homogeneous flow and Poiseuille flow is given for the cooling power $(b)$ and temperature gradient $(c)$, and are plotted against the thermal conductivity

\subsection{Heat loss along the tubes}

For a complete refrigeration device, numerous parallel tubes are necessary to obtain a significant total cooling power. In this case, each tube is surrounded with other tubes, so that the heat exchange between the tubes is limited since all are subjected to the same temperature variations. The only tubes at the boundary of the whole system will exhibit heat exchange with outer medium, which might be negligible for a large number of tubes. On the contrary, for a single tube configuration, it is necessary to consider heat loss along the tube. This configuration is close to laboratory test conditions, and important for the comparison between model and experiment.

The model for the cooling along the $\mathrm{x}$-axis (axis of the tube) starts from the result of the cooling power $P_{M A X}$ and the total thermal conductivity along the tube. The general heat 
transfer equation along $\mathrm{x}$-axis then writes

$$
S_{0} K_{t o t} \frac{\partial^{2} T_{0}}{\partial x^{2}}-h l_{0}\left(T_{0}-T_{e x t}\right)=c_{t o t} \frac{\partial T_{0}}{\partial t}
$$

where $S_{0}, l_{0}, h$ and $c_{t o t}$ are the cross section of the tube, its perimeter, convective heat transfer coefficient with outer medium, and total heat capacity per unit of length respectively. $K_{t o t}$ is the total thermal conductivity, sum of the passive thermal conductivity $K_{\text {passive }}$ in rubber and fluid layers, and of the active thermal conductivity $K_{\text {active. }}$ Their expressions in case of planar configuration are given by Eq. (26) and (27), whereas in case of axisymmetric configuration, it is computed numerically.

General solution of Eq. (35) in steady state ( $\mathrm{T}_{0}$ constant with time) is

$T_{0}(x)=A \cosh (k x)+B \sinh (k x)+c$

with $k^{2}=\frac{h l_{0}}{K_{t o t} S_{0}}$

It is assumed adiabatic boundary condition on both ends of the tube leading to

$$
\begin{aligned}
& S_{0} K_{t o t} \frac{\partial T_{0}}{\partial x}(x=0)=P_{M A X} \\
& S_{0} K_{t o t} \frac{\partial T_{0}}{\partial x}(x=L)=P_{M A X},
\end{aligned}
$$

The total temperature difference between both ends of the tube is finally calculated

$$
T_{0}(x=L)-T_{0}(x=0)=\frac{P_{M A X}}{k S_{0} K_{t o t}}\left(\sinh (k L)-\frac{(1-\cosh (k L))^{2}}{\sinh (k L)}\right)
$$

\section{Experimental setup and results}

An experimental proof of concept was developed in the objective of both proposing an experimental evidence of the elastocaloric cooling of natural rubber, and to give 
reference experimental data that can be compared to the modelling results. It consists of a single rubber tube of initial diameter of $5 \mathrm{~mm}$ and initial length of $25 \mathrm{~mm}$, stretched until an elongation of 6 , leading to a length of $150 \mathrm{~mm}$, and outer diameter of $2 \mathrm{~mm}$ and inner diameter of $1.47 \mathrm{~mm}$. The rubber tube is a purified polyisoprene rubber, purchased to Graham-Field Health Products, Inc., Atlanta, USA (item 3931 series).

It is fixed at both ends to ABS parts that are mounted onto a large displacement actuator on one end (model RSDG312, Misumi Group Inc. Tokyo, Japan), and a fixed point at the other hand. At both ends of the tube, pistons are mounted for pumping fluid into the tube (allowing a maximum pumped volume of $5 \mathrm{ml}$ ), and fixed onto small actuators (model RSD112, Misumi Group Inc. Tokyo, Japan). The three actuators, based on ball screws driving with internal displacement feedback and a precision of $+/$ $20 \mu \mathrm{m}$, are controlled using Matlab® Instrument control toolbox ensuring the synchronization of the actuators commands and the precise control of their displacements. In practical operation, acceleration, speed and positioning are set in order to be as close as possible to a half sine wave.

The temperature is monitored using an infrared camera (model Optris PI 400i, optical lens $29^{\circ}$ x $22^{\circ} / \mathrm{f}=12,7 \mathrm{~mm}$, Optris $\mathrm{GmbH}$, Berlin, Germany), with a resolution of $80 \mathrm{mK}$ and $80 \mathrm{~Hz}$ operation frequency.

A schematic of the experimental setup and a photograph are given in Figure 9. 

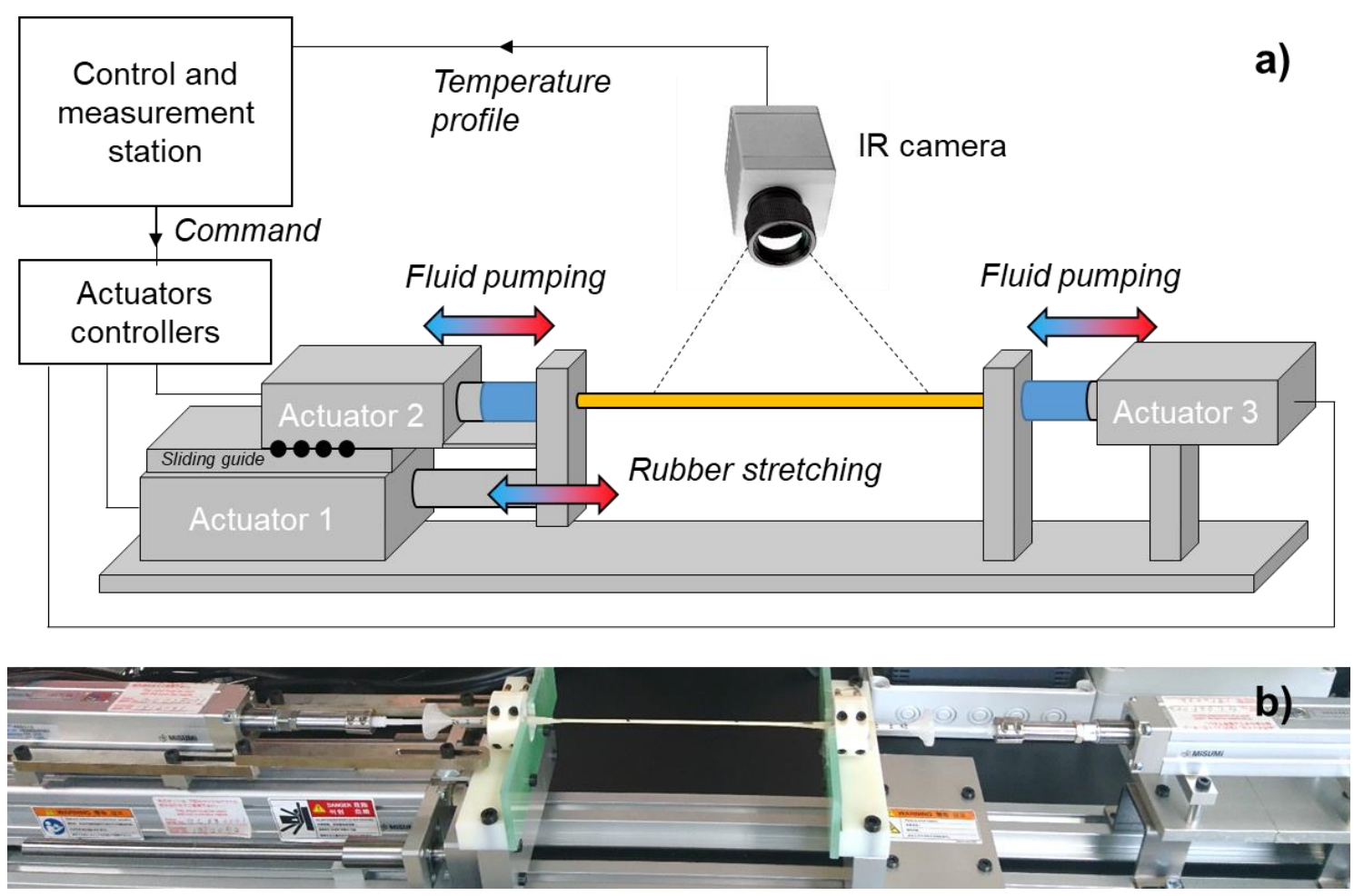

Figure 9: Experimental setup of the regenerative elastocaloric cooling system using natural rubber: schematic (a) and photograph $(b)$

As an example of operation, the rubber was stretched from an elongation of 5 to 6 , leading to an adiabatic temperature change of around $1^{\circ} \mathrm{C}$ monitored in the absence of fluid. At an operating frequency of $0.3 \mathrm{~Hz}$, and a fluid displacement of $1.6 \mathrm{~cm}$ in phase with the rubber stretching, the temperature at two points distant of $57 \mathrm{~mm}$ on the outer edge of the rubber tube was recorded and plotted in Figure 10a. When starting the system, both temperatures starts to oscillate due to the elastocaloric property of rubber. Thanks to the fluid motion, the base line moves exponentially in opposite directions for both points, leading to an overall temperature difference of $1.2^{\circ} \mathrm{C}$ is steady state. When switching off the system, both temperatures moves back to room temperature. In addition, the temperature as a function of $\mathrm{x}$ position was found to be almost linear whatever the testing conditions.

Using the same parameters as for the experiment, the model was computed starting by the determination of the net heat flux along $\mathrm{x}$-axis and the total heat transfer leading to the numerical values of cooling power $P_{M A X}$ and the total thermal 
conductivity along the tube $K_{\text {tot }}$. Then, Eq. (35) was solved using a finite-difference scheme, assuming adiabatic condition on both edges of the cooling line. At one end of the cooling line, the base line of the temperature increases exponentially to a maximum value (corresponding to the solid slowly moving temperature signal in Figure 10b) and decreases to room temperature when the system is switched off. From the temperature amplitudes along the radius of the pipe, the harmonic amplitudes are used to compute the cyclic temperature time variations and are added to the previous simulated base temperature. The total temperature signal on the outer edge of the rubber tube is thus obtained as a function of time, for the same location on the $\mathrm{x}$-axis as for the experiment. The resulting temperature profiles are plotted in Figure $10 \mathrm{~b}$.
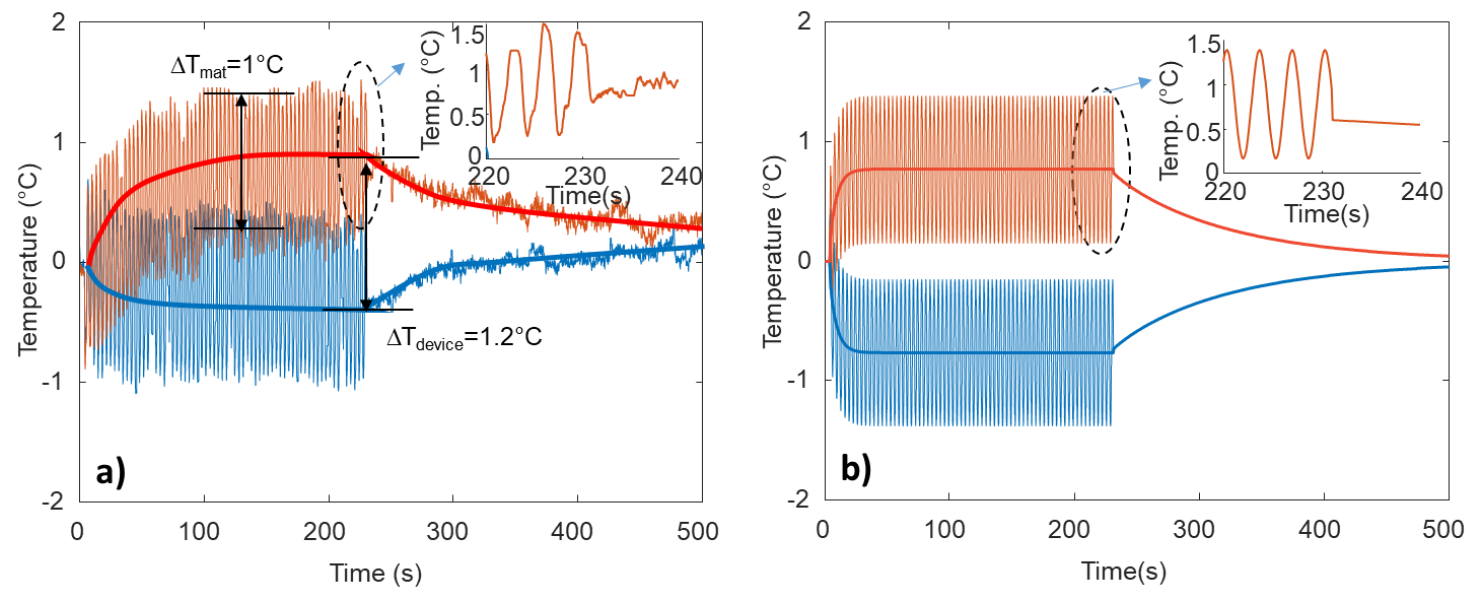

Figure 10: Example of operation of the elastocaloric rubber cooling device for a $0.3 \mathrm{~Hz}$ operation and a fluid displacement of $1.6 \mathrm{~cm}$. The rubber was elongated cyclically between elongations of 5 and 6.a) experimental result and $b$ ), simulated result

Several experimental conditions were then tested, and corresponding simulations were completed accordingly. The experimental conditions are summarized in Table 3. 


\begin{tabular}{|l|l|l|l|}
\hline Property & Symbol & Value & Unit \\
\hline Rubber tube external diameter & $\mathrm{r}_{\mathrm{ext}}$ & 2 & $\mathrm{~mm}$ \\
\hline Rubber tube internal diameter & $\mathrm{r}_{\text {int }}$ & 1.47 & $\mathrm{~mm}$ \\
\hline Rubber tube length & $\mathrm{L}$ & 12.5 & $\mathrm{Cm}$ \\
\hline Fluid displacement amplitude & $\mathrm{U}$ & $1 \sim 5$ & $\mathrm{~cm}$ \\
\hline Adiabatic temperature variation of natural rubber & $\Delta \mathrm{T}_{\mathrm{ad}}$ & 2 & ${ }^{\circ} \mathrm{C}$ \\
\hline Specific heat of natural rubber & $\mathrm{c}_{\text {rubber }}$ & $2 \mathrm{x} 10^{6}$ & $\mathrm{~J} \cdot \mathrm{m}^{-3} \cdot \mathrm{K}^{-1}$ \\
\hline Specific heat of fluid layer & $\mathrm{c}_{\mathrm{fluid}}$ & $4.18 \mathrm{x} 10^{6}$ & $\mathrm{~J} \cdot \mathrm{m}^{-3} \cdot \mathrm{K}^{-1}$ \\
\hline Thermal conductivity of natural rubber & $\mathrm{K}_{\text {rubber }}$ & 0.2 & $\mathrm{~W} \cdot \mathrm{m}^{-1} \cdot \mathrm{K}^{-1}$ \\
\hline Thermal conductivity of fluid layer & $\mathrm{K}_{\text {fluid }}$ & 0.6 & $\mathrm{~W} \cdot \mathrm{m}^{-1} \cdot \mathrm{K}^{-1}$ \\
\hline Frequency of excitation & $\mathrm{f}$ & $0.1 \sim 1$ & $\mathrm{~Hz}$ \\
\hline Phase shift & $\varphi$ & 0 & $\mathrm{rad}$ \\
\hline Surface heat exchange coefficient & $\mathrm{h}$ & 10 & $\mathrm{~W} \cdot \mathrm{m}^{-2} \cdot \mathrm{K}^{-1}$ \\
\hline
\end{tabular}

Table 3: Experimental conditions and parameters for the corresponding simulations

The effect of the fluid displacement was tested with values ranging $5 \mathrm{~mm}$ to 5 $\mathrm{cm}$. For each test, the temperature difference between two points of the cooling line were recorded, and the difference in steady state was used to calculate the mean temperature gradient. The results are displayed in Figure 11.

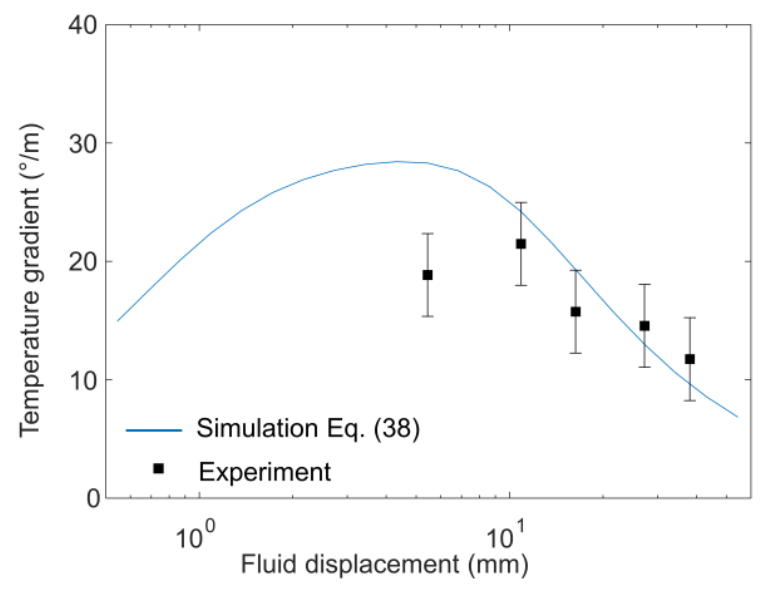


It is observed that temperature gradient decreases with the increase of the fluid displacement, consistently with the increase of the active heat conduction given in Eq. (26) for a parallel layers system. It is reasonable to consider that the axisymmetric problem should also show an increase of the active heat conduction with the square of the fluid displacement, whereas the cooling power is proportional with the fluid displacement. Interestingly, the simulation revealed that the temperature gradient exhibit a maximum value. For very low fluid displacement, the cooling power being very small, the outer losses around the tube are responsible for a lower temperature gradient. It should be noted the experimental point for a fluid displacement of $6 \mathrm{~mm}$, which is far below the theoretical curve. From a practical point of view, such a small displacement of the pistons may lead to an inhomogeneous fluid motion inside the tube, which is flexible and tends to change diameter as a result of pressure change, especially when imperfections in the system exist, such as small air bubbles. Therefore, a higher fluid motion ensures a more homogenous fluid motion. The existence of an optimum fluid displacement amplitude was also observed by other groups, for example such as in [49] for electrocaloric regenerative cooling or in [17,50] for magnetocaloric regenerative cooling. In our experiment and simulation, the optimum displacement is found to be around $10 \%$ of the total length of the cooling system.

Finally, the effect of operating frequency was investigated, for two fluid displacement amplitudes (16mm and $38 \mathrm{~mm})$. The result is displayed in Figure 12. The temperature gradient is found to decrease when decreasing the frequency, as a consequence of the heat losses along the tube. As the cooling power increases with the frequency (as foreseen from Eq.(28)), a higher temperature gradient may be achieved along the tube when increasing the frequency. It is observed also a slight decrease of the gradient for the higher frequencies, which is due to the increase of the active heat conduction along the line, as the speed of the fluid increases with the frequency, as well 
as the decrease of the thermal boundary layer thickness. In addition, from Eq. (28) the cooling power is expected to increase linearly with the displacement amplitude of the fluid, but is associated to a decrease of the temperature gradient as shown in Eq. (29). In Eq. (38) corresponding to the axisymmetric problem, a similar tendency is obtained, where the decrease of the temperature gradient is resulting from the increase of $K_{t o t}$ (due to the active thermal conductivity) which is more important that the increase in cooling power $P_{M A X}$.

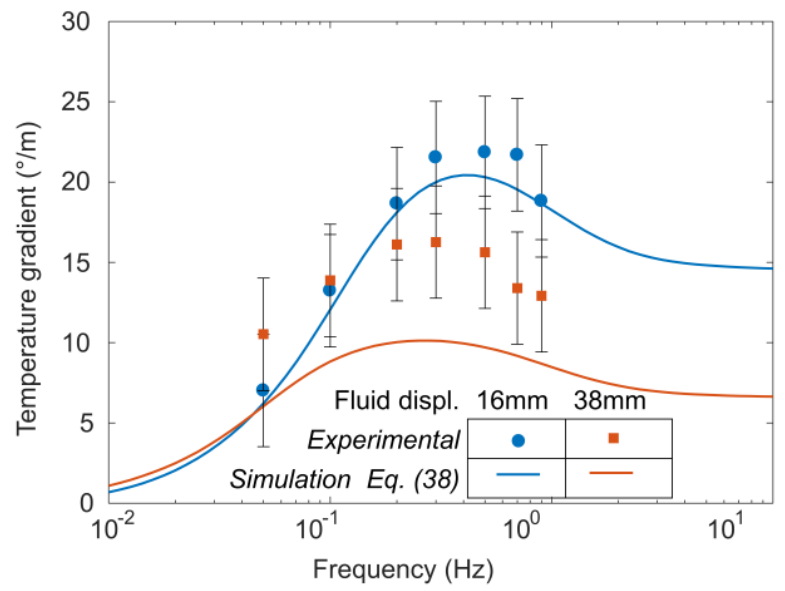

Figure 12: Experiment and simulation of the effect of frequency on the temperature gradient of the elastocaloric cooling system, for two fluid displacement amplitudes. Other parameters are given in Table 3.

It is noticeable that the experimental data show similar trends as the simulation for both the effect of fluid displacement and frequency. It should be noticed that the model considered highly simplified boundary condition at both ends of the tube (adiabatic condition), and the heat losses as well a fluid mixing near the pistons are probably not considered correctly. More precisely, the control of the thermal boundary condition on both edges of the cooling line remains difficult. For large displacement of the fluid, performance is degraded because of a higher inactive fluid volume of the edges, but is enhanced because of a much higher heat exchange with the rubber tube, as well as possible some non-laminar - or at least unsymmetrical fluid flow - due to the geometry uncertainties. As a consequence, the locally turbulent motion of fluid in the vicinity of the rubber may be enhanced leading to a higher heat flux than expected. This 
might explain the discrepancy between model and experiment for large fluid displacement amplitudes, although further investigation remains necessary to assess this discrepancy quantitatively.

\section{Conclusion}

To further develop regenerative cooling using caloric materials, the proposed analytical model gives clear indication about geometrical effects and the relative importance of the properties of the materials. In order to be kept analytical, the model had to be highly simplified and the heat and mass transfer equation was solved successively in a direction perpendicular to an assembly of caloric and fluid layers, and later along the cooling line axis. The use of the harmonic balance solving technique however assumed that the temperature variations reached the steady-state at the scale of the heat transfer along the thickness of the layers. Considering the thickness of thermal boundary layer (in the mm range), and typical characteristic value of thermal diffusivity of rubber and the Nusselt number of fluid, and through an analogy with a plane wall subjected to heat exchange on outer walls, the typical time constant for reaching thermal equilibrium is in the range of a few seconds. Therefore, under harmonic excitation, it is considered that a few periods (for frequency of $0.5 \mathrm{~Hz}$ or below) are sufficient to reach the steady-state regime.

In order to validate the model, a dedicated experiment was prepared, using natural rubber as an elastocaloric material. The model was then adapted to an axisymmetric problem, with the heat transfer equation solving along the radius. Further additional effects were added, such as the fluid front profile, and the heat losses along the rubber tube. The model was then compared to key experiments, showing the influence of fluid displacement amplitude and frequency. Thanks to the reasonable agreement between experiments and model, and considering the model as valid, it was possible to further 
simply it to reach some key figures of merit about material properties.

The solution of the model given along the thickness of the fluid and active material layers is sufficient to determine the net heat flux along the cooling line direction and the maximum achievable temperature gradient if the only limitation is the heat conduction along the cooling line axis. This should to be seen as a limit performance, which is practically degraded by heat losses along the cooling line, and imperfect thermal conditions on the edges of the cooling line (where heat exchangers are placed). Keeping in mind these limitations of the presented approach, and switching back to a parallel layers configuration, an infinite repetition of rubber and water layers can be thus considered. This leads to much simpler - and fully analytical - solutions. The thermal boundary layer thickness is found to play a key role in the regenerative cooling system design. For a boundary layer much larger or much smaller than the thickness of the rubber and water layers, the cooling power drops to zero, showing that both should be of similar orders of magnitude. Natural rubber and water exhibit similar thermal properties, and lead to optimal thickness around $0.2 \sim 1 \mathrm{~mm}$, which is practically feasible. Further increase of the thermal conductivity will require geometry optimization (to keep the thermal boundary layer thickness compatible with those of materials' thickness), and may allow to work with thicker active materials, thus simplifying the device design, although the passive thermal conductivity may degrade the performances.

It should be noted that the model do not consider precisely the boundary conditions at both ends of the cooling line (only a purely adiabatic condition was considered), or the entry effect of the fluid in the tube, which are both difficult to assess in the model and to control experimentally, and that should be considered in future work.

Finally, the experimental proof of concept - which was not the main objective of this work - proved however that the natural rubber works in a regenerative system. 
Further optimization of the device configuration is still needed to increase both temperature gradient and cooling power.

This work focused on harmonic excitation of the cooling system, as the simplest cyclic driving possibility. This allowed an analytical solving for simplified geometries and fluid flows, with the possibility to use numerical solutions of the equations for more complex geometry and realistic fluid flow profiles. For improving the cooling device performance, it may be preferred more efficient thermodynamic cycles, like Brayton cycle, Ericsson cycles, or its combination [51], that may bring higher performances. These are based on implementing phase shift and non-harmonic signals (like square shape). These signals can be decomposed in harmonic components, and in future work, it is foreseen that the model proposed in this article can compute the individual response of each of them, and then to assess the performances by summing up individual response.

\section{Acknowledgements:}

This work was supported by ANR through the project ECPOR (ANR-17-CE05-0016), and by the Japanese Society for the Promotion of Science (JSPS) through the Grant-inAid for Scientific Research (grant no. 19K04230).

The authors gratefully acknowledge the French Region Auvergne-Rhône-Alpes, the French project IDEXLYON of the Université de Lyon in the framework of the "Investissements d'Avenir" program (ANR-16-IDEX-0005).

\section{References}

1. Calm JM. 2008 The next generation of refrigerants - Historical review, considerations, and outlook. Int. J. Refrig. 31, 1123-1133. (doi:10.1016/j.ijrefrig.2008.01.013) 
2. Crossley S, Mathur ND, Moya X. 2015 New developments in caloric materials for cooling applications. AIP Adv. 5, 067153. (doi:10.1063/1.4922871)

3. Kitanovski A, Plaznik U, Tomc U, Poredoš A. 2015 Present and future caloric refrigeration and heat-pump technologies. Int. J. Refrig. 57, 288-298. (doi:10.1016/j.ijrefrig.2015.06.008)

4. Barclay JA, Steyert WA. 1982 Materials for magnetic refrigeration between $2 \mathrm{~K}$ and 20 K. Cryogenics (Guildf). 22, 73-80. (doi:10.1016/0011-2275(82)90098-4)

5. Balli M, Fruchart D, Gignoux D, Dupuis C, Kedous-Lebouc A, Zach R. 2008 Giant magnetocaloric effect in Mn1-x(Ti0.5V0.5)xAs: Experiments and calculations. J. Appl. Phys. 103, 103908. (doi:10.1063/1.2917323)

6. Pecharsky VK, Gschneidner, Jr. KA. 1997 Giant Magnetocaloric Effect in Gd5(Si2Ge2). Phys. Rev. Lett. (doi:10.1103/PhysRevLett.78.4494)

7. Mischenko AS, Zhang Q, Scott JF, Whatmore RW, Mathur ND. 2006 Giant electrocaloric effect in thin-film PbZr0.95Ti0.05O3. Science (80-. ). 311, 12701271. (doi:10.1126/science.1123811)

8. Neese B, Chu B, Lu S-G, Wang Y, Furman E, Zhang QM. 2008 Large electrocaloric effect in ferroelectric polymers near room temperature. Science 321, 821-3. (doi:10.1126/science.1159655)

9. Valant M. 2012 Electrocaloric materials for future solid-state refrigeration technologies. Prog. $\quad$ Mater. Sci. $\quad$ 57, 980-1009. (doi:10.1016/j.pmatsci.2012.02.001) 
10. Chukka R, Vandrangi S, Shannigrahi S, Chen L. 2013 An electrocaloric device demonstrator for solid-state cooling. EPL (Europhysics Lett. 103, 47011. (doi:10.1209/0295-5075/103/47011)

11. Defay E, Faye R, Despesse G, Strozyk H, Sette D, Crossley S, Moya X, Mathur ND. 2018 Enhanced electrocaloric efficiency via energy recovery. Nat. Commun. 9, 1827. (doi:10.1038/s41467-018-04027-9)

12. Feng D, Yao S-C, Zhang T, Zhang Q. 2016 Modeling of a Smart Heat Pump Made of Laminated Thermoelectric and Electrocaloric Materials. J. Electron. Packag. 138, 041004. (doi:10.1115/1.4034751)

13. Wang Y, Schwartz DE, Smullin SJ, Wang Q, Sheridan MJ. 2017 Silicon Heat Switches for Electrocaloric Cooling. J. Microelectromechanical Syst. 26, 580587. (doi:10.1109/JMEMS.2017.2676704)

14. Zhang T, Qian X-S, Gu H, Hou Y, Zhang QM. 2017 An electrocaloric refrigerator with direct solid to solid regeneration. Appl. Phys. Lett. 110, 243503. (doi:10.1063/1.4986508)

15. Bruederlin F, Ossmer H, Wendler F, Miyazaki S, Kohl M. 2017 SMA foil-based elastocaloric cooling: from material behavior to device engineering. J. Phys. D. Appl. Phys. 50, 424003. (doi:10.1088/1361-6463/aa87a2)

16. Ossmer H, Wendler F, Gueltig M, Lambrecht F, Miyazaki S, Kohl M. 2016 Energy-efficient miniature-scale heat pumping based on shape memory alloys. Smart Mater. Struct. 25, 085037. (doi:10.1088/0964-1726/25/8/085037)

17. Bahl CRH, Petersen TF, Pryds N, Smith A. 2008 A versatile magnetic refrigeration test device. Rev. Sci. Instrum. 79, 093906. (doi:10.1063/1.2981692) 
18. Qian S, Geng Y, Wang Y, Ling J, Hwang Y, Radermacher R, Takeuchi I, Cui J. 2016 A review of elastocaloric cooling: Materials, cycles and system integrations. Int. J. Refrig. 64, 1-19. (doi:10.1016/j.ijrefrig.2015.12.001)

19. Brown G V. 1976 Magnetic heat pumping near room temperature. J. Appl. Phys. 47, 3673-3680. (doi:10.1063/1.323176)

20. Sinyavsky Y V., Brodyansky VM. 1992 Experimental testing of electrocaloric cooling with transparent ferroelectric ceramic as a working body. Ferroelectrics 131, 321-325. (doi:10.1080/00150199208223433)

21. Sinyavskii Y V. 1995 Electrocaloric refrigerators: A promising alternative to current low-temperature apparatus. Chem. Pet. Eng. 31, 295-306. (doi:10.1007/BF01148217)

22. Sinyavskii Y V. 1995 Analysis of the efficiency of an electrocaloric cryorefrigerator. Chem. Pet. Eng. 31, 501-506. (doi:10.1007/BF01152032)

23. Sinyavsky YV, Lugansky GE, Pashkov ND. 1992 Electrocaloric refrigeration: Investigation of a model and prognosis of mass and efficiency indexes. Cryogenics (Guildf). 32, 28-31. (doi:10.1016/0011-2275(92)90102-G)

24. Qian S, Geng Y, Wang Y, Muehlbauer J, Ling J, Hwang Y, Radermacher R, Takeuchi I. 2016 Design of a hydraulically driven compressive elastocaloric cooling system. Sci. Technol. Built Environ. 22, 500-506. (doi:10.1080/23744731.2016.1171630)

25. Engelbrecht K, Tušek J, Eriksen D, Lei T, Lee C-Y, Tušek J, Pryds N. 2017 A regenerative elastocaloric device: experimental results. J. Phys. D. Appl. Phys. 50, 424006. (doi:10.1088/1361-6463/aa8656) 
26. Tušek J, Engelbrecht K, Eriksen D, Dall'Olio S, Tušek J, Pryds N. 2016 A regenerative elastocaloric heat pump. Nat. Energy 1, 16134. (doi:10.1038/nenergy.2016.134)

27. Gu H, Qian X, Li X, Craven B, Zhu W, Cheng A, Yao SC, Zhang QM. 2013 A chip scale electrocaloric effect based cooling device. Appl. Phys. Lett. 102. (doi:12290410.1063/1.4799283)

28. Plaznik U et al. 2015 Bulk relaxor ferroelectric ceramics as a working body for an electrocaloric cooling device. Appl. Phys. Lett. 106, 043903. (doi:10.1063/1.4907258)

29. Gu H, Qian X-S, Ye H-J, Zhang QM. 2014 An electrocaloric refrigerator without external regenerator. Appl. Phys. Lett. 105, 162905. (doi:10.1063/1.4898812)

30. Blumenthal P, Molin C, Gebhardt S, Raatz A. 2016 Active electrocaloric demonstrator for direct comparison of PMN-PT bulk and multilayer samples. Ferroelectrics 497, 1-8. (doi:10.1080/00150193.2016.1160466)

31. Matsuo T, Azuma N, Toriyama Y, Yoshioka T. 2016 Mechanocaloric properties of poly(dimethylsiloxane) and ethylene-propylene rubbers. J. Therm. Anal. Calorim. 123, 1817-1824. (doi:10.1007/s10973-015-4675-0)

32. Yoshida Y, Yuse K, Guyomar D, Capsal J-F, Sebald G. 2016 Elastocaloric effect in poly(vinylidene fluoride-trifluoroethylene-chlorotrifluoroethylene) terpolymer. Appl. Phys. Lett. 108, 242904. (doi:10.1063/1.4953770)

33. Xie Z, Sebald G, Guyomar D. 2016 Comparison of direct and indirect measurement of the elastocaloric effect in natural rubber. Appl. Phys. Lett. 108, 041901. (doi:10.1063/1.4940378) 
34. Xie Z, Sebald G, Guyomar D. 2015 Elastocaloric effect dependence on preelongation in natural rubber. Appl. Phys. Lett. 107, 081905. (doi:10.1063/1.4929395)

35. Aprea C, Greco A, Maiorino A, Masselli C. 2017 A two-dimensional model of a solid-state regenerator based on combined electrocaloric-elastocaloric effect. Energy Procedia 126, 337-344. (doi:10.1016/j.egypro.2017.08.225)

36. Trevizoli P V., Barbosa JR. 2017 Thermal-hydraulic behavior and influence of carryover losses in oscillating-flow regenerators. Int. J. Therm. Sci. 113, 89-99. (doi:10.1016/j.ijthermalsci.2016.11.002)

37. Qian S, Alabdulkarem A, Ling J, Muehlbauer J, Hwang Y, Radermacher R, Takeuchi I. 2015 Performance enhancement of a compressive thermoelastic cooling system using multi-objective optimization and novel designs. Int. J. Refrig. 57, 62-76. (doi:10.1016/j.ijrefrig.2015.04.012)

38. Qian S, Ling J, Hwang Y, Radermacher R, Takeuchi I. 2015 Thermodynamics cycle analysis and numerical modeling of thermoelastic cooling systems. Int. J. Refrig. 56, 65-80. (doi:10.1016/j.ijrefrig.2015.04.001)

39. Aprea C, Greco A, Maiorino A, Masselli C. 2016 A comparison between different materials in an active electrocaloric regenerative cycle with a $2 \mathrm{D}$ numerical model. Int. J. Refrig. 69, 369-382. (doi:10.1016/j.ijrefrig.2016.06.016)

40. Qian S, Yuan L, Yu J, Yan G. 2017 Numerical modeling of an active elastocaloric regenerator refrigerator with phase transformation kinetics and the matching principle for materials selection. Energy 141, 744-756. (doi:10.1016/j.energy.2017.09.116) 
41. Luo D, Feng Y, Verma P. 2017 Modeling and analysis of an integrated solid state elastocaloric heat pumping system. Energy 130, 500-514. (doi:10.1016/j.energy.2017.05.008)

42. Gu H, Craven B, Qian X, Li X, Cheng A, Zhang QM. 2013 Simulation of chipsize electrocaloric refrigerator with high cooling-power density. Appl. Phys. Lett. 102. (doi:112901 10.1063/1.4796184)

43. Tijani H, Spoelstra S, Poignand G. 2008 Study of a thermoacoustic-Stirling engine. J. Acoust. Soc. Am. 123, 3541-3541. (doi:10.1121/1.2934525)

44. Poignand G, Lihoreau B, Lotton P, Gaviot E, Bruneau M, Gusev V. 2007 Optimal acoustic fields in compact thermoacoustic refrigerators. Appl. Acoust. 68, 642-659. (doi:10.1016/j.apacoust.2006.03.009)

45. Lotton P, Blanc-Benon P, Bruneau M, Gusev V, Duffourd S, Mironov M, Poignand G. 2009 Transient temperature profile inside thermoacoustic refrigerators. Int. J. Heat Mass Transf. 52, 4986-4996. (doi:10.1016/j.ijheatmasstransfer.2009.03.075)

46. Landau LD, Lifshitz EM. 1987 CHAPTER V - THERMAL CONDUCTION IN FLUIDS. In Fluid Mechanics, pp. 192-226. Pergamon Press plc. Published by Elsevier Ltd. (doi:10.1016/B978-0-08-033933-7.50013-1)

47. Swift GW. 1988 Thermoacoustic engines. J. Acoust. Soc. Am. 84, 1145-1180. (doi:10.1121/1.396617)

48. Tušek J, Engelbrecht K, Mikkelsen LP, Pryds N. 2015 Elastocaloric effect of NiTi wire for application in a cooling device. J. Appl. Phys. 117, 124901. (doi:10.1063/1.4913878) 
49. Plaznik U, Vrabelj M, Kutnjak Z, Malič B, Rožič B, Poredoš A, Kitanovski A. 2019 Numerical modelling and experimental validation of a regenerative electrocaloric cooler. Int. J. Refrig. $\quad \mathbf{9 8}, \quad 139-149$. (doi:10.1016/j.ijrefrig.2018.10.029)

50. Mugica I, Poncet S, Bouchard J. 2018 An open source DNS solver for the simulation of Active Magnetocaloric Regenerative cycles. Appl. Therm. Eng. 141, 600-616. (doi:10.1016/j.applthermaleng.2018.06.007)

51. Plaznik U, Tušek J, Kitanovski A, Poredoš A. 2013 Numerical and experimental analyses of different magnetic thermodynamic cycles with an active magnetic $\begin{array}{llll}\text { regenerator. } & \text { Appl. } & \text { Therm. } & \text { Eng. }\end{array}$ (doi:10.1016/j.applthermaleng.2013.05.019)

\section{$\underline{\text { Table captions }}$}

Table 1 : Parameters used in the simulation of a three layers configuration

Table 2 : Parameters used in the simulation for testing the effect of thermal conductivity

Table 3: Experimental conditions and parameters for the corresponding simulations

\section{$\underline{\text { Figure captions }}$}

Figure 1 : Configuration of the regenerative cooling system consisting of coplanar infinite layers of caloric material or fluid of thickness $h_{i}$.

Figure 2 : Typical result of the simulation for a $1 \mathrm{~Hz}$ excitation and $1 \mathrm{~mm}$ fluid layer thickness: a) amplitude and phase of the temperature variations for both rubber (located $-1.5 \mathrm{~mm}<\mathrm{z}<-0.5 \mathrm{~mm}$ and $0.5 \mathrm{~mm}>\mathrm{z}>1.5 \mathrm{~mm}$ ) and fluid (located $0.5 \mathrm{~mm}>\mathrm{z}>0.5 \mathrm{~mm}$ ), and for a temperature gradient of $-2{ }^{\circ} \mathrm{C} / \mathrm{cm}, \mathrm{b}$ ) for $0 \% \mathrm{~cm}$ and c) for $+2^{\circ} \mathrm{C} / \mathrm{cm}$. In $\mathrm{d}$ ), the overall heat flux (per unit of width) is plotted against the temperature gradient, thus highlighting the maximum heat flux (for null temperature gradient), and the maximal temperature gradient fort when the heat flux becomes null. The slope of this curve corresponds to the effect of the thermal conductivity. 
Figure 3 : Effect of the total number of layers of fluid and elastocaloric material on the cooling power and maximum temperature gradient

Figure 4 : Effect of the thickness of fluid layer on cooling performances at $0.1 \mathrm{~Hz}$ : a) surface cooling power and b) maximal temperature gradient along $\mathrm{x}$ axis. For $\mathrm{a}$ frequency of $1 \mathrm{~Hz}$ : c) surface cooling power and d) maximal temperature gradient. On each graph, the black curve is obtained using full model with 31 layers, whereas dotted red line is resulting from (24) and (27).

Figure 5 : Effect of thermal conductivity of fluid layer on the cooling power (a) and on the temperature gradient (b)

Figure 6 : Comparison between active and passive heat conductivities in case of an infinite repetition of elastocaloric material layer and fluid layer

Figure 7 : Comparison between simplified expressions and complete model in case of an infinite repetition of elastocaloric material layer and fluid layer

Figure 8: Simulation of Poiseuille flow using successive concentric tubes of fluid at different speeds. a) Resulting speed and temperature variation amplitude. The comparison between homogeneous flow and Poiseuille flow is given for the cooling power (b) and temperature gradient (c), and are plotted against the thermal conductivity

Figure 9: Experimental setup of the regenerative elastocaloric cooling system using natural rubber: schematic (a) and photograph (b)

Figure 10: Example of operation of the elastocaloric rubber cooling device for a $0.3 \mathrm{~Hz}$ operation and a fluid displacement of $1.6 \mathrm{~cm}$. The rubber was elongated cyclically between elongations of 5 and 6.a) experimental result and b), simulated result

Figure 11: Experiment and simulation of the effect of the fluid displacement on the temperature gradient. The frequency was set to $0.3 \mathrm{~Hz}$. Other parameters are given in Table 3.

Figure 12: Experiment and simulation of the effect of frequency on the temperature gradient of the elastocaloric cooling system, for two fluid displacement amplitudes. Other parameters are given in Table 3. 